\title{
Numerical Analysis and Experimental Verification of Optimum Heat Input in Additive Manufacturing of Aero Ultrathin Blade
}

\author{
Shijie Dai $\mathbb{D}^{1},{ }^{1}$ Miao Gong $\mathbb{D},{ }^{1,2}$ Liwen Wang $\mathbb{D}^{2},{ }^{2}$ and Tao Wang $\mathbb{D}^{2}$ \\ ${ }^{1}$ School of Mechanical Engineering, Hebei University of Technology, Tianjin 300041, China \\ ${ }^{2}$ Institute of Aviation Engineering, Civil Aviation University of China, Tianjinc 300300, China \\ Correspondence should be addressed to Miao Gong; mgong69@163.com
}

Received 3 May 2020; Revised 5 January 2021; Accepted 16 January 2021; Published 30 January 2021

Academic Editor: Parviz Ghadimi

Copyright (c) 2021 Shijie Dai et al. This is an open access article distributed under the Creative Commons Attribution License, which permits unrestricted use, distribution, and reproduction in any medium, provided the original work is properly cited.

Heat input is a crucial factor affecting the quality in blade additive manufacturing repairing. First, a moving heat source model was established, and through numerical analysis and experimental comparison, the optimal geometric parameters of the heat source model for ultrathin blade repair were obtained. Second, a heat transfer model is established based on the optimal heat source model. By analyzing the thermophysical properties of different alloys, the heat input range of the blade was calculated. By heat transfer calculation under different heat inputs, the heat transfer model of blade repair was optimized. Then, a mathematical model of additive height is established. The optimized heat transfer model is used to solve the temperature distribution of the additive section with time under different wire feeding speeds through numerical analysis, which further reduced the heat input range. Third, the experiments are carried out based on the results of numerical analysis. The evolution law of the microstructure and heat input rate of the additive manufacturing zone was revealed, and the optimal heat input parameters were obtained. Under the optimal parameters, the segregation zone disappeared; hence, the test data were close to the base metal, and the additive manufacturing zone achieved better quality. The results and methods are of great guiding significance for the optimization design in additive manufacturing repair of the aero blades. The study also contributes to carrying out a series of research on heat transfer of ultrathin nickel-based alloy welding.

\section{Introduction}

Inconel 718 is a nickel-based superalloy which is strengthened by face-centered cube $\gamma^{\prime}\left(\mathrm{Ni}_{3} \mathrm{X}\right.$ with $X=\mathrm{Nb}$, Ti, or $\left.\mathrm{Al}\right)$ and body-centered cube $\gamma^{\prime \prime}\left(\mathrm{Ni}_{3} \mathrm{Nb}\right)[1,2]$. It is widely used in the aviation and aerospace industries because of its good properties. In the civil aviation field, the 4-9 stage blades of a large number of new engine compressors are made of nickelbased alloy. The repair step for the tip crack is to remove the damaged part and repair by additive manufacturing, which can be considered as the first stage of repair and then polish it into the original shape after heat treatment, which can be considered as the second stage of repair. Among them, the additive manufacturing quality in the first stage is particularly important [3]. The additive manufacturing of the blade is high standard welding, which is the most important step affecting blade postrepair performance.
The heat input is a key factor affecting the microstructure and properties of the weld zone in the welding process of alloy [4-6]. The amount of heat input directly affects the temperature and cooling rate of the molten pool [7-9]. The excessive temperature will significantly increase the grain size of the weld and base metal [10]. When the thickness of the material is small, the effect is more significant $[11,12]$. Durocher and Richards [13] point out that voltage and current were the most significant process parameters affecting the crack density of microwelded deposits and that using lower values for voltage and current reduces void content and crack density. The study of Saravanan et al. [14] investigated the properties of different heat input zones with different macrostructures for low, middle, and higher heat input, respectively. Wu et al. [15] reviewed the status and existing problems of numerical simulation of composite heat source welding process, 
discussed the research direction and development trend of the field of surfacing welding, and provided the theoretical basis for the optimization of welding process and process control.

Due to its high strength and coarse-grain size, the cast alloy suffers from microfissuring in the weld heat-affected zone (HAZ) as a result of elemental segregation or grain boundary liquation during the weld cycle [16, 17]. The molten pool will precipitate niobium carbides during the cooling process between 1280 and $1265^{\circ} \mathrm{C}$, and their formations have detrimental effects on the weld strength [18]. Ye et al. $[19,20]$ studied the microstructure change of Inconel 718 alloy sheet under TIG welding and put forward an effective method to reduce hot crack by properly reducing heat input. Wang et al. [21] pointed out that larger heat input reduces the cooling rate of the molten pool, and $\mathrm{Nb}$ and $\mathrm{Mo}$ segregation directly leads to the formation of Laves phase. The larger heat input causes the slower cooling rate of the molten pool, the lower the content of $\gamma$ phase in the microstructure of residual liquid transformation, and the more eutectic composition. When the cooling rate is increased by adjusting the heat input, the content of the $\gamma$ phase increases and the segregation rate decreases obviously. Manikandan et al. $[22,23]$ studied the method of controlling heat input to restrain $\mathrm{Nb}$ segregation and reduce Laves phase formation between dendrites. In addition, according to the research in [21], they further pointed out that Mo has a lower diffusion rate and higher density than $\mathrm{Nb}$, so the segregation of $\mathrm{Nb}$ is more important for the influence of microstructure after welding.

The previously published research results are mainly about the welding of thick plates, and the repair method is mostly butt-welding with a higher power. However, there are few reports on additive manufacturing by welding of ultrathin Inconel 718 alloys under $2 \mathrm{~mm}$. New engine compressor blades use ultrathin nickel-based alloys with a partial tip thickness less than $1.5 \mathrm{~mm}$, which is more difficult to repair by surfacing. The two main additive manufacturing repair methods currently used are microplasma arc welding (MPAW) and laser cladding [24, 25]. Compared with laser cladding, MPAW is one of the low-cost metal joining techniques for the microscale application due to its inherent properties of controlling constricted arc with low amperage current [26].

In order to achieve good additive manufacturing quality in blade repairing, it is very important to solve the optimal heat input and the corresponding parameters. Based on MPAW additive manufacturing repair, this study aims to obtain a good matching scheme of heat input and related parameters through theoretical modeling, numerical analysis, and experimental verification.

\section{Heat Source Modeling and Numerical Analysis}

2.1. Model of Moving Heat Source. The material of the compressor blade tip is ultrathin alloy, and its dimensions are very small. According to the repair standard, only the tip damage within $2 \mathrm{~mm}$ is repaired by surfacing welding.
During the MPAW process, the wire has deposited the surface of the base material after being melted by a heat source. With the movement of the welding gun, the heat from the welding gun forms a trailing circle [27] on the molten pool, which can be called a double ellipse [28]. Due to shallower melting depth, the double ellipsoid heat source model can be simplified to a double elliptical surface distribution heat source and consider only the heat flow distribution in the $x-y$ plane. Figure 1 (a) is a schematic diagram of a heat source of a double elliptical surface distribution. In Figure 1(b), $b_{h}$ is the short semiaxis of the ellipse, $a_{f}$ is the semiaxis of the front ellipse, and $a_{r}$ is the semimajor axis at the back of the ellipse.

The front half of the heat source can be expressed as

$$
q_{f}(x, y)=q_{1} \exp \left(-A_{1} x^{2}-B_{1} y^{2}\right)
$$

where $q_{1}$ represents the maximum heat flux density and $A_{2}$ and $B_{2}$ are shape parameters. The back half of the heat source can be expressed as

$$
q_{r}(x, y)=q_{2} \exp \left(-A_{2} x^{2}-B_{2} y^{2}\right)
$$

where $q_{2}$ represents the maximum heat flux density and $A_{2}$ and $B_{2}$ are shape parameters. The energy of the front half of the heat source can be expressed as

$$
\begin{aligned}
Q_{f} & =2 \int_{0}^{\infty} \int_{0}^{\infty} q_{1} \exp \left(-A_{1} x^{2}-B_{1} y^{2}\right) \mathrm{d} x \mathrm{~d} y \\
& =2 q_{1} \int_{0}^{\infty} \exp \left(-A_{1} x^{2}\right) \mathrm{d} x \int_{0}^{\infty} \exp \left(-B_{1} y^{2}\right) \mathrm{d} y .
\end{aligned}
$$

After calculation,

$$
Q_{f}=2 q_{1}\left(\frac{1}{\sqrt{A_{1}}} \frac{\sqrt{\pi}}{2}\right)\left(\frac{1}{\sqrt{B_{1}}} \frac{\sqrt{\pi}}{2}\right)=q_{1} \frac{\pi}{2 \sqrt{A_{1} B_{1}}} .
$$

Since $95 \%$ of the heat is in the heated spot, substituting into $\left(0, b_{h}\right)$ gives

$$
\begin{aligned}
q_{f}\left(0, b_{h}\right) & =q_{1} \exp \left(-B_{1} b_{h}^{2}\right)=0.05 q_{1}, \\
B_{1} & =\frac{3}{b_{h}^{2}} .
\end{aligned}
$$

Similarly, it can be derived that

$$
A_{1}=\frac{3}{a_{f}^{2}} \text {. }
$$

The heat flux density distribution formula at the front of the double ellipse can be expressed as

$$
q_{f}(x, y)=\frac{6 Q_{f}}{\pi a_{f} b_{h}} \exp \left(-\frac{3 x^{2}}{a_{f}^{2}}-\frac{3 y^{2}}{b_{h}^{2}}\right), \quad x \geq 0 .
$$

The heat flux density distribution formula at the back of the double ellipse can be expressed as

$$
q_{r}(x, y)=\frac{6 Q_{r}}{\pi a_{r} b_{h}} \exp \left(-\frac{3 x^{2}}{a_{r}^{2}}-\frac{3 y^{2}}{b_{h}^{2}}\right), \quad x<0,
$$




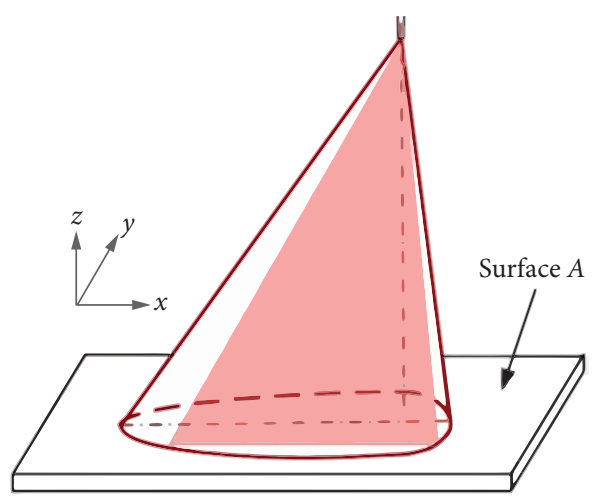

(a)

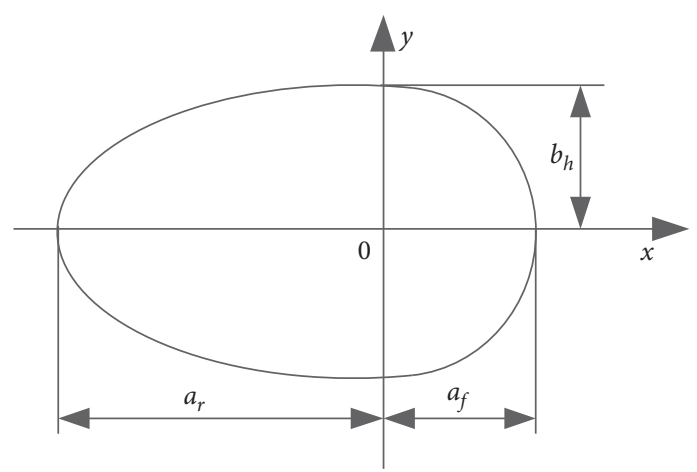

(b)

FIGURE 1: Schematic diagram of double ellipse distribution region. (a) Double elliptical surface distribution. (b) Heat flow distribution in the $x-y$ plane.

where $Q_{f}$ and $Q_{r}$ represent the energy of the double elliptical heat source acting on the front and back regions, respectively. Among them,

$$
\begin{aligned}
Q & =\eta I U=Q_{f}+Q_{r}, \\
Q_{f} & =\frac{a_{f}}{a_{f}+a_{r}} Q, \\
Q_{r} & =\frac{a_{r}}{a_{f}+a_{r}} Q,
\end{aligned}
$$

where $Q$ represents the total energy of the double elliptical heat source and $\eta$ represents thermal efficiency of the welding heat source, and its value is related to welding method, welding material, and welding environment. $U$ represents the welding voltage, and $I$ represents the welding current. Since the welding process is a dynamic process, if the welding heat source moves at a speed of $v$ and the welding direction is along the positive direction of the $x$-axis, the front expression of the moving welding heat source model is

$$
q_{f}(x, y, t)=\frac{6 Q_{f}}{\pi a_{f} b_{h}} \exp \left(-\frac{3(x-v t)^{2}}{a_{f}^{2}}-\frac{3 y^{2}}{b_{h}^{2}}\right), \quad x \geq 0 .
$$

The front expression of the moving welding heat source model is

$$
q_{r}(x, y, t)=\frac{6 Q_{r}}{\pi a_{r} b_{h}} \exp \left(-\frac{3(x-v t)^{2}}{a_{r}^{2}}-\frac{3 y^{2}}{b_{h}^{2}}\right), \quad x<0 .
$$

According to the mathematical model of the mobile heat source, the mobile heat source model is built by COMSOL Multiphysics simulation software, as shown in Figure 2. The heat flow gradient of the former is steep and gentle in the latter. It shows the phenomenon of heat dragging in the moving process, which is consistent with the actual heat flux distribution of the welding heat source.
2.2. Finite Element Model of Heat Transfer Structure. The structure of the blade MPAW repairing fixture is shown in Figure 3. The fixture is mainly composed of a copper heat dissipation clamping structure and an aluminum frame. Two groups of horizontally movable copper blocks like piano keys are mounted on the clamping structure. Since the heat dissipation is mainly concentrated on the portion of the copper fixture close to the clamping surface, the model design only considered the copper clamping structure for simplifying the calculation. Considering that the part curvature of the blade clamped is small, in this study, $1 \mathrm{~mm}$ thick Inconel 718 alloy rectangular sheet was used to simulate the compressor blade. The size of alloy specimens is $65 \mathrm{~mm} \times 30 \mathrm{~mm} \times 1 \mathrm{~mm}$. Since the fixture is a symmetrical structure, in order to simplify the calculation, half of the section of the test piece is taken as a plane of symmetry, and a finite element model is established; the meshing and mass distribution are shown in Figure 4. A dense mesh was applied to the upper surface of the test piece and the front and upper ends of the copper block, and the rest is applied with a loose mesh. The grid contains 215,852 units, of which the smallest unit size is $1.79 \times 10^{-5} \mathrm{~m}$, maximum unit size is $0.00179 \mathrm{~m}$, the maximum unit growth rate is 1.3 , and the average grid quality is 0.6522 .

2.3. Derivation and Transformation of Heat Transfer Equation of the Model. According to the theory document of "Heat Transfer Module" of COMSOL Multiphysics, based on the first law of thermodynamics [29], the heat balance equation of blade additive manufacturing repair is

$$
\begin{aligned}
\rho \frac{\partial E}{\partial t}+\rho \mathbf{u} \cdot \nabla E+\nabla \cdot\left(\mathbf{q}+\mathbf{q}_{r}\right) & =\sigma: \mathbf{D}+Q, \\
\mathbf{q} & =-k \nabla T .
\end{aligned}
$$

The basic equation of the solid heat transfer part of the model is 

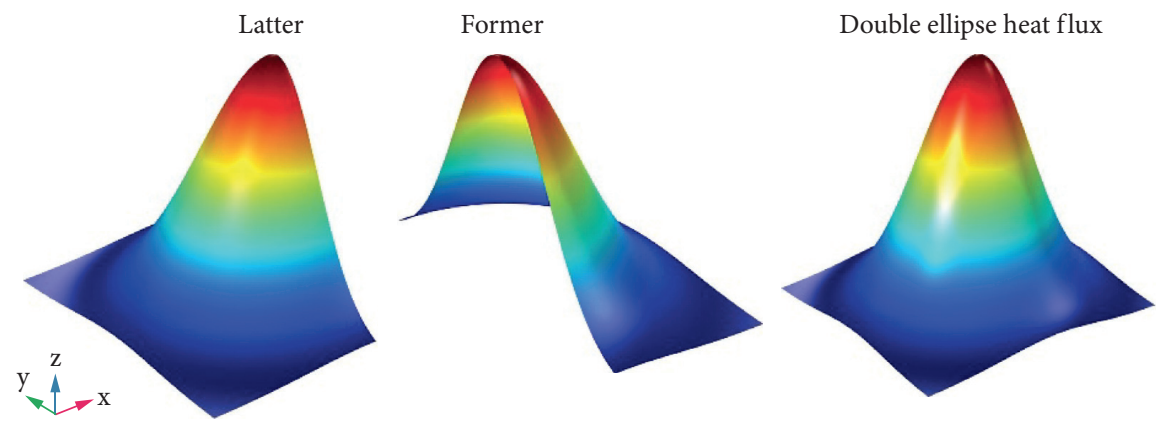

Figure 2: Model of double ellipse heat flux.

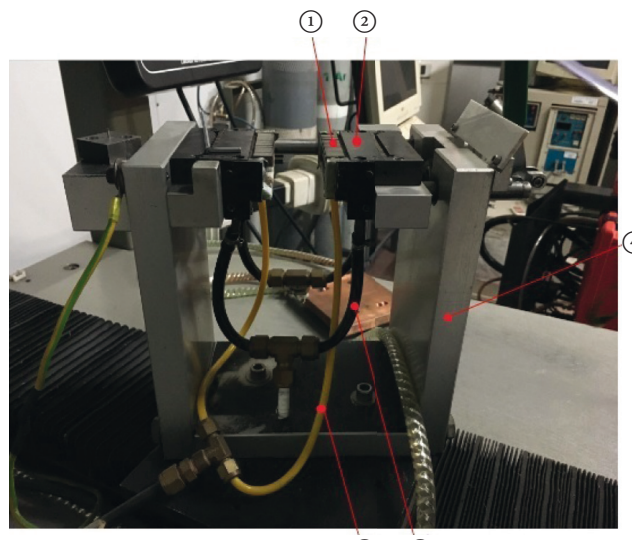

(5) (6)

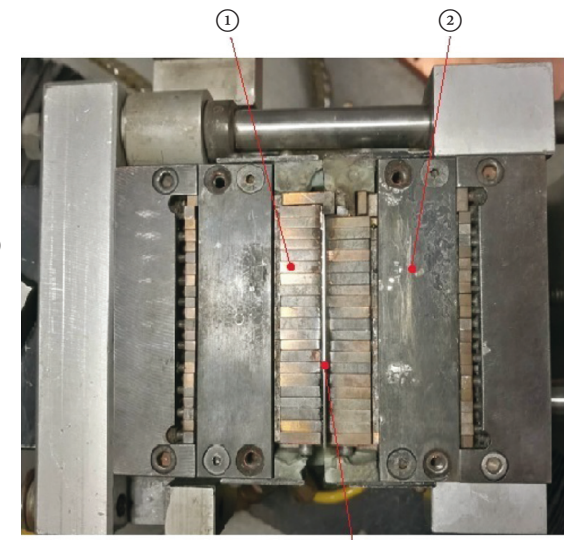

(3)

Figure 3: MPAW repair fixture. (1): movable copper block. (2): clamping structure. (3): welding test piece. (4): aluminum frame. (5): protective gas pipeline. (6): coolant pipeline.

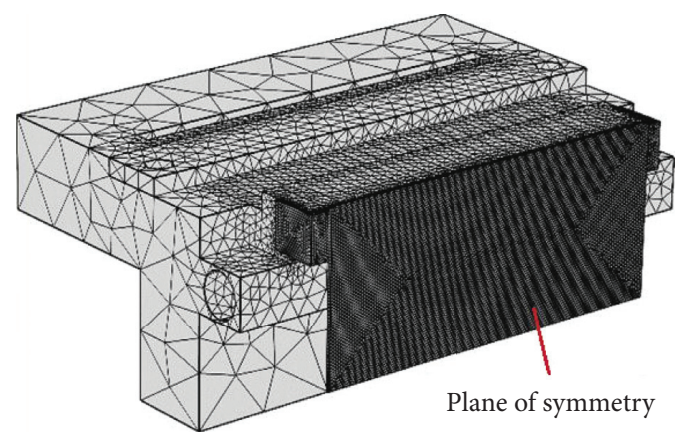

(a)

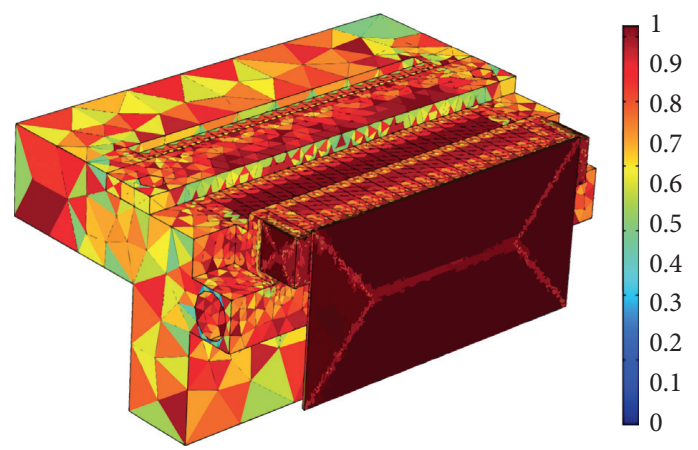

(b)

FIgURE 4: Meshing and mass distribution. (a) Finite element mesh generation and symmetry surface location. (b) Mesh quality.

$$
\begin{array}{r}
\rho C_{p}\left(\frac{\partial T}{\partial t}+\mathbf{u}_{\text {trans }} \cdot \nabla T\right)+\nabla \cdot\left(\mathbf{q}+\mathbf{q}_{r}\right)=Q_{\text {ted }}+Q \\
Q_{\text {ted }}=-\alpha T: \frac{d S}{\mathrm{~d} t},
\end{array}
$$

where $Q_{\text {ted }}$ is the thermoelastic damping considering the effect in the solid, $\rho$ is the density, $C p$ is the constant pressure heat capacity, $T$ is the absolute temperature, $\mathbf{u}_{\text {trans }}$ is the translation velocity vector, $\mathbf{q}$ is the conduction heat flux, $\mathbf{q}_{r}$ is the radiant heat flux, $\alpha$ is the coefficient of thermal expansion, $S$ is the second-order Piola-Kirchhoff stress tensor, and $Q$ is the external heat source.

Because the thickness of the test piece in the model is only $1 \mathrm{~mm}$, the local solid heat transfer from the molten pool to the fixture is considered as thin structure heat transfer. Moreover, since the heat transfer is mainly along the tangential direction of the thin structure, it is expressed as a heat-thin approximation problem by 


$$
d_{s} \rho \frac{\partial E}{\partial t}+d_{s} \rho \mathbf{u} \cdot \nabla_{t} E+\nabla_{t} \cdot\left(\mathbf{q}_{s}+\mathbf{q}_{r}\right)=-d_{s}(\sigma: \mathbf{D})+d_{s} Q+q_{0}
$$

$$
\mathbf{q}_{s}=-d_{s} k \nabla_{t} T,
$$

where $k$ is the thermal conductivity, $d_{s}$ is the thickness of the layer, $Q$ is the density of the heat source distributed in the layer, and $q_{0}$ is the received out of plane heat flow. When the equation is solved between the copper blocks and the blade, the exchange heat flow of blade and copper is according to the following conditions:

$$
q_{0}=\mathbf{n} \cdot \mathbf{q},
$$

where $\mathbf{n}$ is the normal vector toward the outside. In the coupling relationship between the blade and the copper blocks, the output heat flux $\mathbf{n} \cdot \mathbf{q}$ is received by the adjacent thin layer as the boundary in the source term $q_{0}$. Neglecting the thermoelastic effect in this area, the calculation equation of heat transfer in the simulation process can be set as

$$
-\mathbf{n} \cdot \mathbf{q}=d_{s} Q_{s}-d_{s} \rho \frac{\partial E}{\partial t}-\left(d_{s} \rho \mathbf{u} \cdot \nabla_{t} E\right)-\nabla_{t} \cdot\left(\mathbf{q}_{s}+\mathbf{q}_{r}\right) .
$$

There is convective heat transfer between the blade and the shielding gas, and the shielding gas participates in the heat transfer of the molten pool to a certain extent, so it needs to be considered in the modeling. In addition, considering the diffuse reflection, define the external side of the fixture, the external side of the copper key and the side of the blade as the diffuse reflection surface. The heat transfer process between blade weld and surrounding argon during welding is expressed by

$$
-k_{1}(\nabla T \cdot \mathbf{n})=q_{w}-h_{0}\left(T-T_{0}\right)-\varepsilon_{t} \sigma\left(T^{4}-T_{0}^{4}\right),
$$

where $k_{1}$ is the thermal conductivity of the test piece, $q_{w}$ represents the absorbed heat flux, and $h_{0}$ represents the surface thermal conductivity between the test piece and the shielding gas. $T$ and $T_{0}$ represent the weld bead temperature and ambient temperature, respectively. $\varepsilon_{t}$ is the surface emissivity, $\sigma$ is the Boltzmann radiation constant, and $\varepsilon_{t} \sigma\left(T^{4}-T_{0}^{4}\right)$ represents the diffuse reflection surface heat flux.

In the same way, considering that the upper surface of the copper blocks is affected by the refraction from the shielding gas, the convective heat transfer coefficient of the surface increases, and the heat transfer process between the copper blocks and the surrounding gas is expressed as

$$
-k_{2}(\nabla T \cdot \mathbf{n})=q_{1}-h_{2}\left(T_{2}-T_{0}\right)-\varepsilon_{c} \sigma\left(T_{2}^{4}-T_{0}^{4}\right),
$$

where $k_{2}$ is the thermal conductivity of copper blocks, $q_{1}$ is the heat received by copper block, $h_{2}$ is the convective heat transfer coefficient between copper blocks and argon, and $\varepsilon_{c}$ is the surface emissivity of copper block.

In addition, the latent heat of phase change is considered in the process of additive manufacturing repair because the alloy is a kind of impure material. The region and material of the phase change part are defined in the model, and the calculation equation is established. Assuming that the phase transition temperature of the material is $\mathrm{T}_{\mathrm{PC}}$, the transition occurs in the temperature range between $T_{p c}-\Delta T / 2$ and $T_{p c}+\Delta T / 2$. In this range, a smooth function $\theta$ represents the phase fraction before the phase transition is established. $\theta$ is 1 before $T_{p c}-\Delta T / 2$ and 0 after $T_{p c}+\Delta T / 2$. Then, the density, $\rho$, and enthalpy, $H$, are expressed by

$$
\begin{aligned}
\rho & =\theta \rho_{\mathrm{ph} 1}+(1-\theta) \rho_{\mathrm{ph} 2}, \\
H & =\frac{1}{\rho}\left(\theta \rho_{\mathrm{ph} 1} H_{\mathrm{ph} 1}+(1-\theta) \rho_{\mathrm{ph} 2} H_{\mathrm{ph} 2}\right),
\end{aligned}
$$

where indexes ph1 and ph2 indicate the material in phase 1 or phase 2, respectively. Differentiating with respect to temperature, this equality provides the following formula for the specific heat capacity:

$$
C_{p}=\frac{\partial H}{\partial T}
$$

which becomes, after some formal transformations,

$$
C_{p}=\frac{1}{\rho}\left(\theta_{1} \rho_{\mathrm{ph} 1} C_{p, \mathrm{ph} 1}+\theta_{2} \rho_{\mathrm{ph} 2} C_{p, \mathrm{ph} 2}\right)+\left(H_{\mathrm{ph} 2}-H_{\mathrm{ph} 1}\right) \frac{d \alpha_{m}}{d T},
$$

where $\theta_{1}$ and $\theta_{2}$ are equal to $\theta$ and $1-\theta$, respectively. The relationship between mass fraction $\alpha_{m}$ and $\rho_{p h 1}, \rho_{p h 2}$, and $\theta$ is as follows:

$$
\alpha_{m}=\frac{1}{2} \frac{\theta_{2} \rho_{\mathrm{ph} 2}-\theta_{1} \rho_{\mathrm{ph} 1}}{\rho} .
$$

It is equal to $-1 / 2$ before transformation and $1 / 2$ after transformation. The specific heat capacity is the sum of an equivalent heat capacity:

$$
C_{\mathrm{eq}}=\frac{1}{\rho}\left(\theta_{1} \rho_{\mathrm{ph} 1} C_{p, \mathrm{ph} 1}+\theta_{2} \rho_{\mathrm{ph} 2} C_{p, \mathrm{ph} 2}\right) .
$$

The distribution of latent heat $C_{L}$ is

$$
C_{L}(T)=\left(H_{\mathrm{ph} 2}-H_{\mathrm{ph} 1}\right) \frac{d \alpha_{m}}{d T} .
$$

Therefore, the expression of apparent heat capacity $\mathrm{C}_{p}$ used for phase change materials in the phase change region in the model heat equation is given by

$$
C_{p}=\frac{1}{\rho}\left(\theta_{1} \rho_{\mathrm{ph} 1} C_{p, \mathrm{ph} 1}+\theta_{2} \rho_{\mathrm{ph} 2} C_{p, \mathrm{ph} 2}\right)+C_{L} .
$$

2.4. Model Parameters Analysis. The chemical composition (wt.\%) of Inconel 718 base metal test piece and welding wire in this study is shown in Table 1.

The surfacing process is to melt the wire and clad it on the surface of the base metal. After cooling and solidification, the welding wire and base metal are well integrated. In the calculation, the average composition of the two materials is taken as the basis of calculation, and the thermophysical 
TABle 1: The chemical composition (wt.\%) of Inconel 718.

\begin{tabular}{lcccccccccccc}
\hline & $\mathrm{Al}$ & $\mathrm{C}$ & $\mathrm{Co}$ & $\mathrm{Cr}$ & $\mathrm{Cu}$ & $\mathrm{Fe}$ & $\mathrm{Mn}$ & $\mathrm{Mo}$ & $\mathrm{Nb}$ & $\mathrm{Ni}$ & $\mathrm{Si}$ & $\mathrm{Ti}$ \\
\hline Base metal & 0.39 & 0.052 & 0.05 & 19.0 & 0.17 & 16.7 & 0.29 & 2.93 & 4.97 & 54.3 & 0.26 & 0.9 \\
Wire & 0.56 & 0.033 & 0.15 & 18.6 & 0.056 & 18.03 & 0.12 & 2.98 & 4.85 & 53.6 & 0.10 & 0.92 \\
Avg. & 0.475 & 0.0425 & 0.10 & 18.8 & 0.113 & 17.365 & 0.205 & 2.955 & 4.91 & 53.95 & 0.18 & 0.91 \\
\hline
\end{tabular}

parameters of the materials are calculated by using JMatPro software. According to the report provided by the material manufacturer, the heat treatment temperature is set to $980^{\circ} \mathrm{C}$ and the upper limit is set to $1600^{\circ} \mathrm{C}$; then, the sampling temperature interval is 10 to $50^{\circ} \mathrm{C}$, and the calculation is carried out many times. The calculation results of the main thermophysical parameters are shown in Figure 5.

2.5. Numerical Analysis of Heat Source Model. The thickness of the alloy piece is $1 \mathrm{~mm}$, the diameter of the welding wire is $0.8 \mathrm{~mm}$, and the heat source section needs to cover the molten pool completely. Therefore, it is assumed that the parameters of the double ellipse are $a_{f}=1.5 \mathrm{~mm}$, $b_{h}=1.5 \mathrm{~mm}, a_{r}=1.9 \mathrm{~mm}$, and the heat source power is $330 \mathrm{~W}$ which is based on the previous study [30] of TC4 blades. The three-dimensional model of the moving heat source is simulated as shown in Figure 6. The maximum heat flux density is $1.24 \times 10^{8} \mathrm{~W} / \mathrm{m}^{2}$, and the minimum heat flux density is $3.06 \times 10^{5} \mathrm{~W} / \mathrm{m}^{2}$. In order to distinguish it from the following research models, this model is defined as the hypothetical heat source model 1 .

The microsection $d s(t)$ of the upper surface of the molten pool directly opposite to the heat source center is taken as the key position. The microsections are shown schematically in red mark in Figure 7(a). With the movement of the welding gun, the coordinates of the heat source center on the upper surface of the molten pool change continuously, which makes the average temperature of the corresponding microsection to change accordingly. The average temperature of the microsections can be considered as the maximum temperature of the molten pool at that time.

Take the stable period of $2 \sim 48 \mathrm{~s}$ as the research object, and the average temperature of the microsection at different times is shown in Figure 7(b). It is shown that the temperature fluctuation range of the molten pool is about $2210 \sim$ $2365^{\circ} \mathrm{C}$, and the overall average temperature is about $2270^{\circ} \mathrm{C}$.

Figure 7 (b) reflects the dynamic change of the temperature field before the formation of the steady-state from the perspective of microsection. The temperature fluctuation of the molten pool can reflect the transient accumulation of heat [31-33]. The welding heat input, wire feeding speed, and cooling rate are the possible reasons for the temperature fluctuation of the molten pool. The liquid fluidity of Inconel 718 alloy is poor, and because of the good thermal conductivity of the copper bond fixture and the large temperature difference between the fixture, base metal, and molten pool, the longitudinal heat conduction to base metal is larger. Temperature accumulation of the molten pool microsection will also affect the temperature fluctuation of the weld cross section, which may affect the microstructure of the weld zone. The average temperature analysis method of the microsection can also be applied to the analysis of temperature distribution of the welding seam.

2.6. Experiment of Thermal Monitoring. In order to verify and optimize the numerical model, with the same heat input power of $330 \mathrm{~W}$, the experimental parameters are shown in Table 2, where $t$-s represents arc-starting time and $t$-e represents arc stopping time. Then, we compared the numerical analysis results with the experiments' results.

By the measurement of the FLIR Heat Camera, the maximum temperature of the molten pool is detected that the fluctuation range is between $1770^{\circ} \mathrm{C}$ and $1830^{\circ} \mathrm{C}$ at different times and four typical monitoring pictures with stability time more than $2 \mathrm{~s}$ are intercepted as shown in Figure 8. According to the monitoring results, the average maximum temperature of Inconel 718 is about $1800.8^{\circ} \mathrm{C}$.

The results show that, under the same heat source power, the maximum temperature of the molten pool calculated by hypothetical model 1 is significantly higher than that measured by experiment, and the average temperature difference is about $470^{\circ} \mathrm{C}$. Obviously, the heat flux of hypothetical model 1 is larger.

\subsection{Adjustment and Optimization of Heat Source Model.} Through the analysis of the error causes because the geometric parameters of the heat source model cannot be set into welding machine, it can be inferred that the main cause of the error is the difference of the heat source concentration between the numerical model and the actual welding gun. The double ellipse area of the heat source on the $x-y$ plane is small, and the heat source concentration is too high, which leads to the high calculation temperature of heat source model 1. Therefore, in the following numerical analysis, the geometric size of the double ellipse is adjusted and the numerical analysis is carried out, respectively.

By adjusting the size of the heat source, the three-dimensional geometry of the heat source with different heat concentrations is shown in Figure 9. The results show that, with the increase of the geometry size of the double ellipse on the $x-y$ plane, the heat source concentration tends to decrease regularly. The corresponding model parameters are shown in Table 3.

Figure 15 shows the change of heat flow density corresponding to different heat source concentrations. It is shown that, with the increase of double ellipse geometry, the maximum heat flow density and the minimum heat flow density show a linear downward trend and have a good linearity.

With different heat source concentrations according to the parameters in Table 3, the numerical analysis results of the maximum temperature variation of the molten pool are 


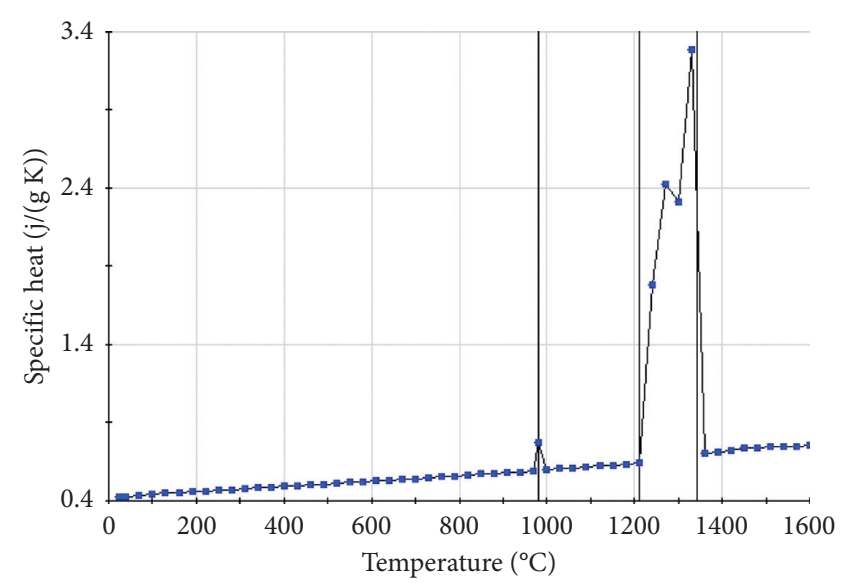

(a)

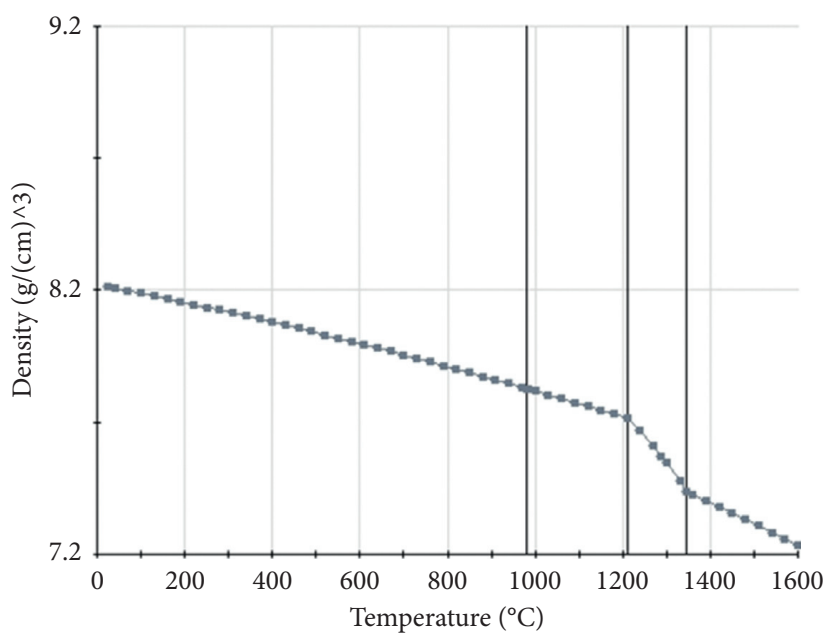

(c)

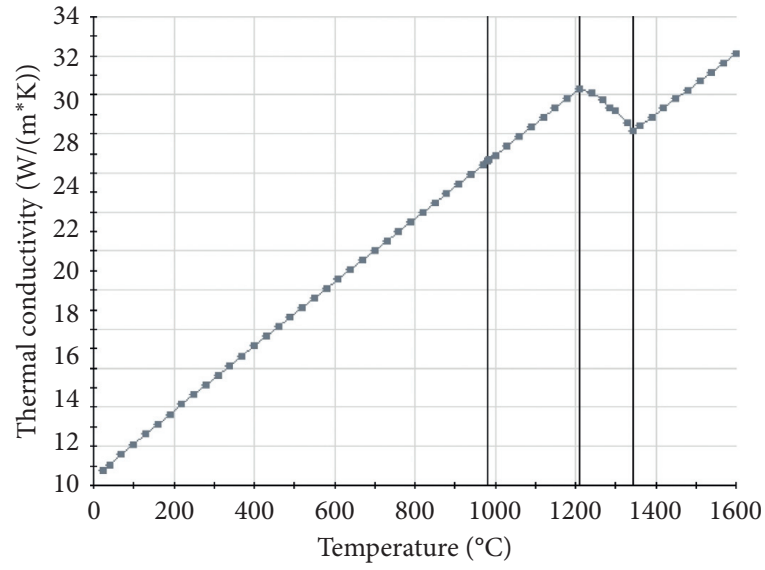

(b)

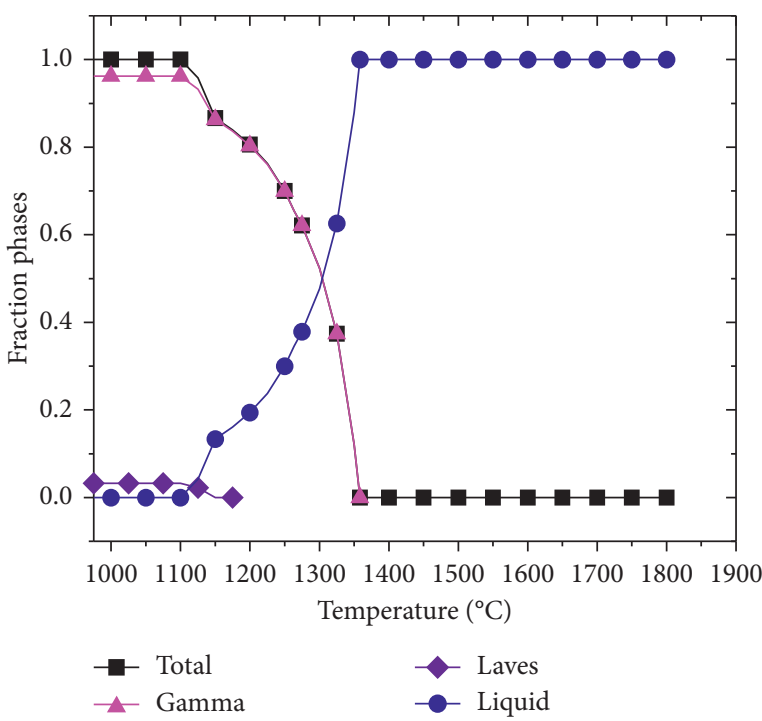

(d)

Figure 5: Thermal physical properties of the material: (a) specific heat, (b) thermal conductivity, (c) density, and (d) wt. \% phase.

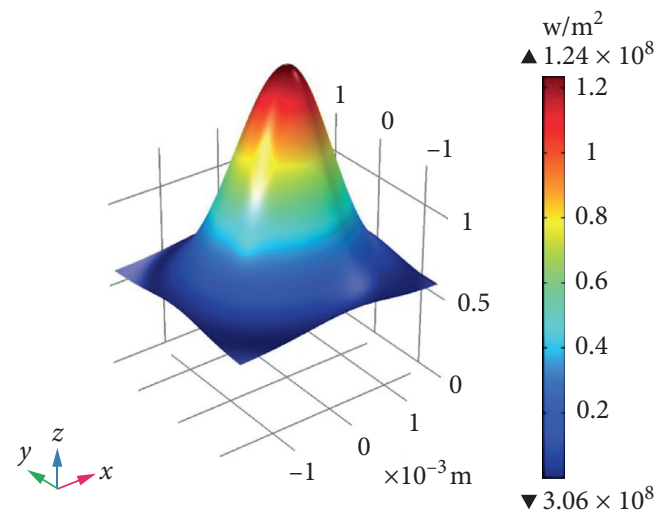

FIGURE 6: The three-dimensional model of the moving heat source (hypothetical model 1).

shown in Figures 10-14. After calculation, the average value of the maximum temperature is shown in Table 4 . The results show that changing the heat concentration by adjusting the geometric size of the heat source can effectively reduce the error with the experiment.

The maximum temperature of the molten pool lowered with the decrease of heat concentration. The average value of the maximum temperature calculated by model 3 is about $1880^{\circ} \mathrm{C}$ and model 4 is about $1780^{\circ} \mathrm{C}$. Comparing with the experimental data, the error of model 4 is about $-21^{\circ} \mathrm{C}$ and the error of model 3 is about $+80^{\circ} \mathrm{C}$. Although the error of model 4 is the smallest, if considering the heat loss in the actual process, the calculation result of the numerical model should not be less than the experimental monitoring result, so the heat source concentration of model 3 will be more suitable.

Through further verification of model 3 , the time when the heat source moves above the central position of the test piece is selected to calculate the isothermal surface distribution of the molten pool, as shown in Figure 16. The results show that the molten temperature on this position is about $1898^{\circ} \mathrm{C}$, and the isothermal surface is approximately symmetrical distribution. From the temperature gradient, the longitudinal isothermal surface spacing of the specimen 


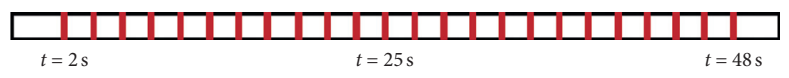

(a)

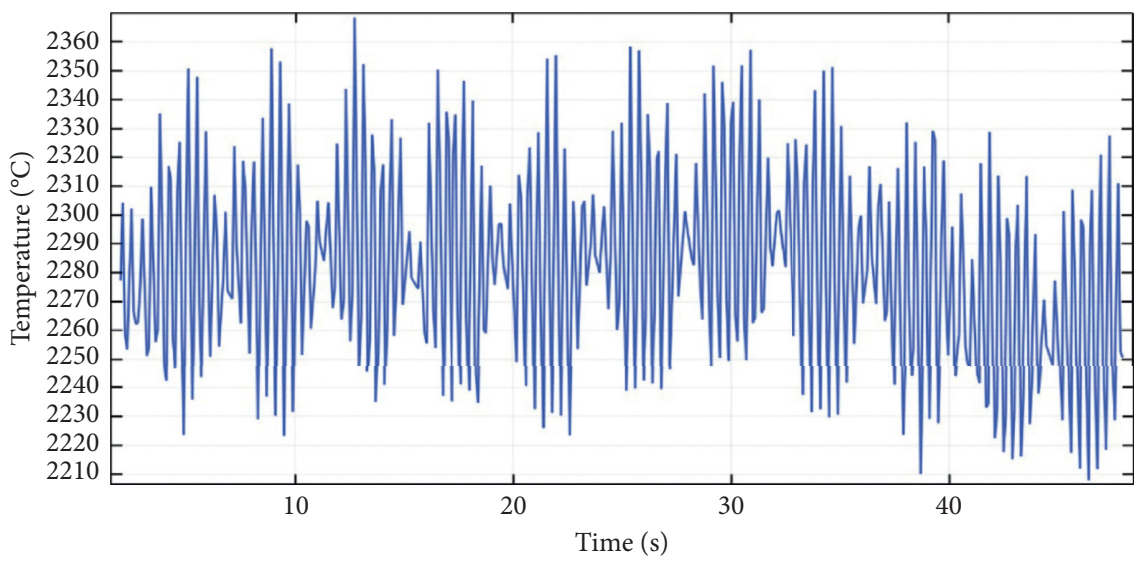

(b)

FIGURE 7: The distribution of the maximum temperature of molten pool with time (model 1). (a) Microsections of the upper surface of the molten pool directly opposite to the heat source center. (b) The average temperature of the microsection at different times.

TABLE 2: Experimental parameters of heat source model validation.

\begin{tabular}{ccccccc}
\hline$\alpha$ & $\eta$ & $U(\mathrm{~V})$ & $I(\mathrm{~A})$ & Welding speed (in/min) & $t$-s $(\mathrm{s})$ & $t-e(\mathrm{~s})$ \\
\hline 1 & 0.8 & 18 & 18.4 & 3 & 0.2 & 0.2 \\
\hline
\end{tabular}
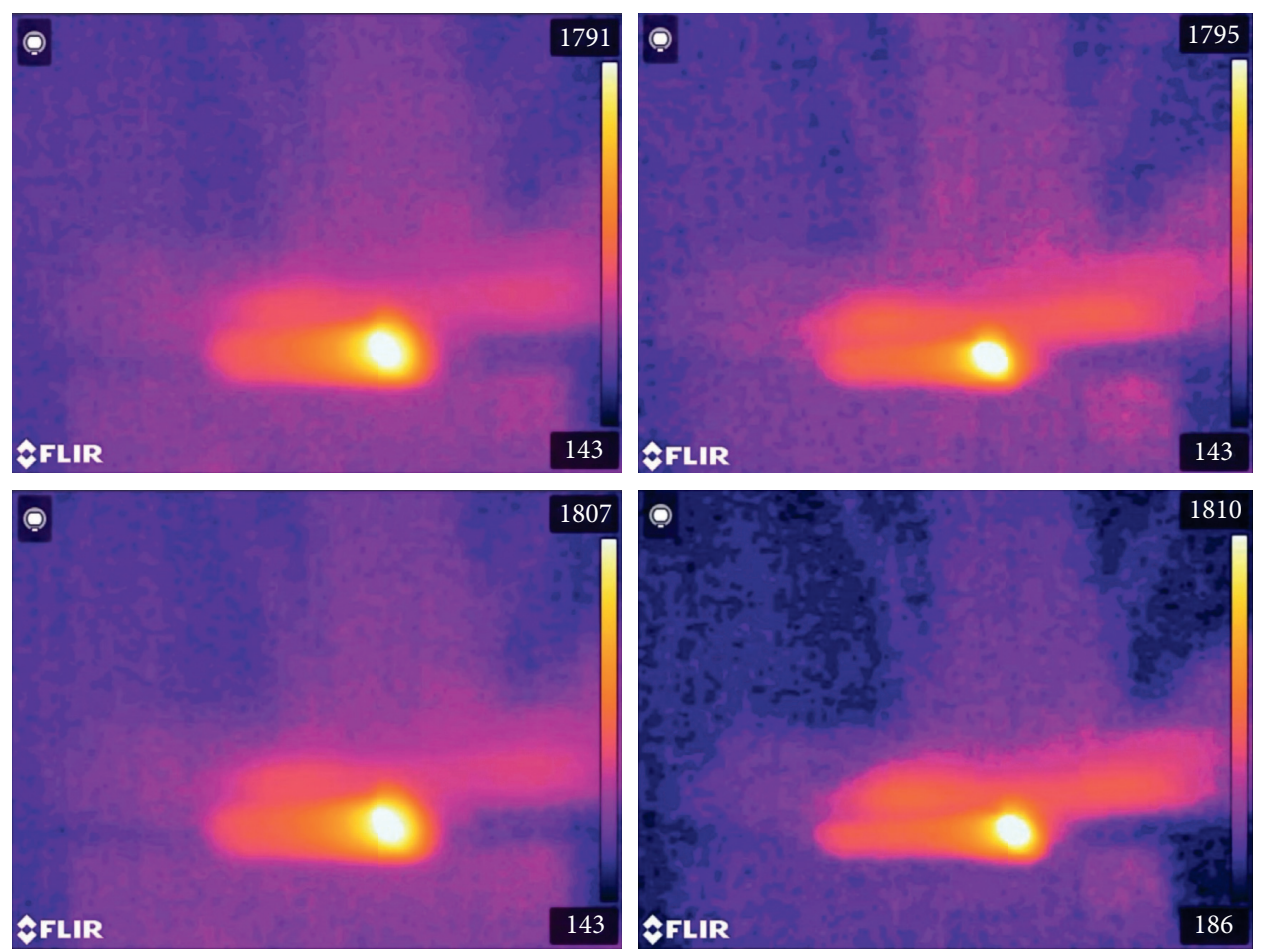

FIGURE 8: Thermal imaging monitoring screen.

along the $z$-axis is obviously smaller than that of the horizontal direction, indicating that the temperature gradient in the horizontal direction is obviously smaller than that in the longitudinal direction.
According to the above comparative analysis, a more accurate numerical model can be obtained by adjusting the geometry of the double ellipse, which can change the concentration of the heat source well. Considering the 

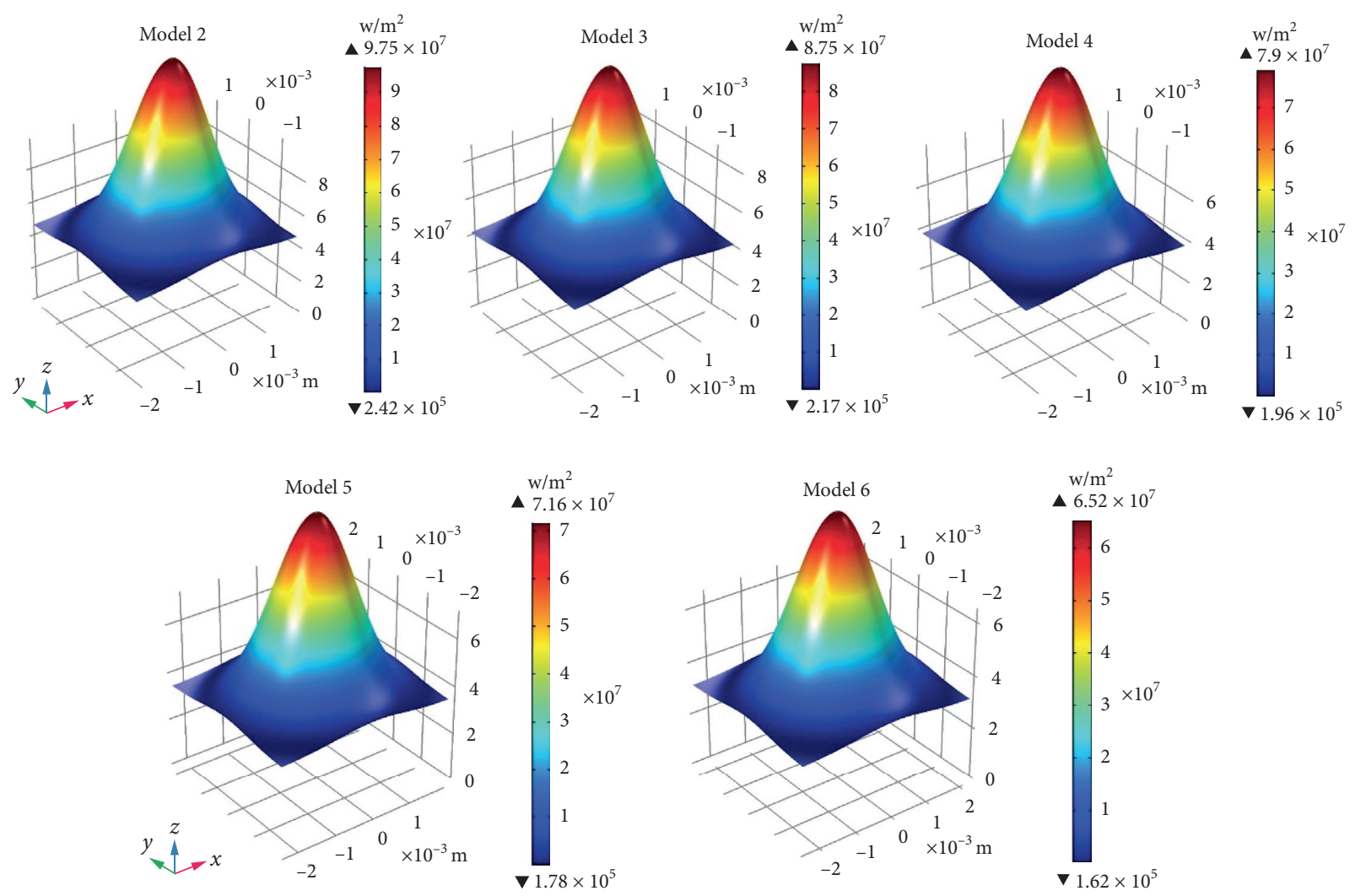

Figure 9: The three-dimensional shape under different heat source concentrations.

TABLE 3: Adjustment parameter and curve number of heat source concentration.

\begin{tabular}{lcccc}
\hline Model number & $a_{f}(\mathrm{~mm})$ & $b_{h}(\mathrm{~mm})$ & $a_{r}(\mathrm{~mm})$ & \\
\hline 2 & 1.7 & 1.7 & 2.1 & Curve \\
3 & 1.8 & 1.8 & 2.2 & Figure 10 \\
4 & 1.9 & 1.9 & 2.3 & Figure 11 \\
5 & 2.0 & 2.0 & 2.4 & Figure 12 \\
6 & 2.1 & 2.1 & 2.5 & Figure 13 \\
\hline
\end{tabular}

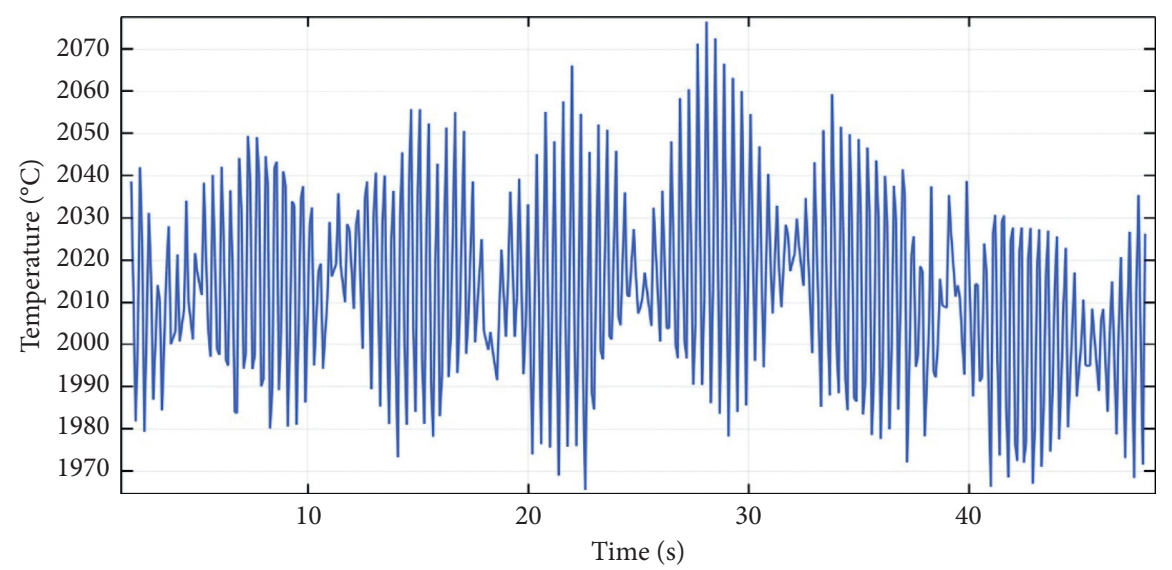

FIgURE 10: The distribution of the maximum temperature of molten pool with time (model 2). 


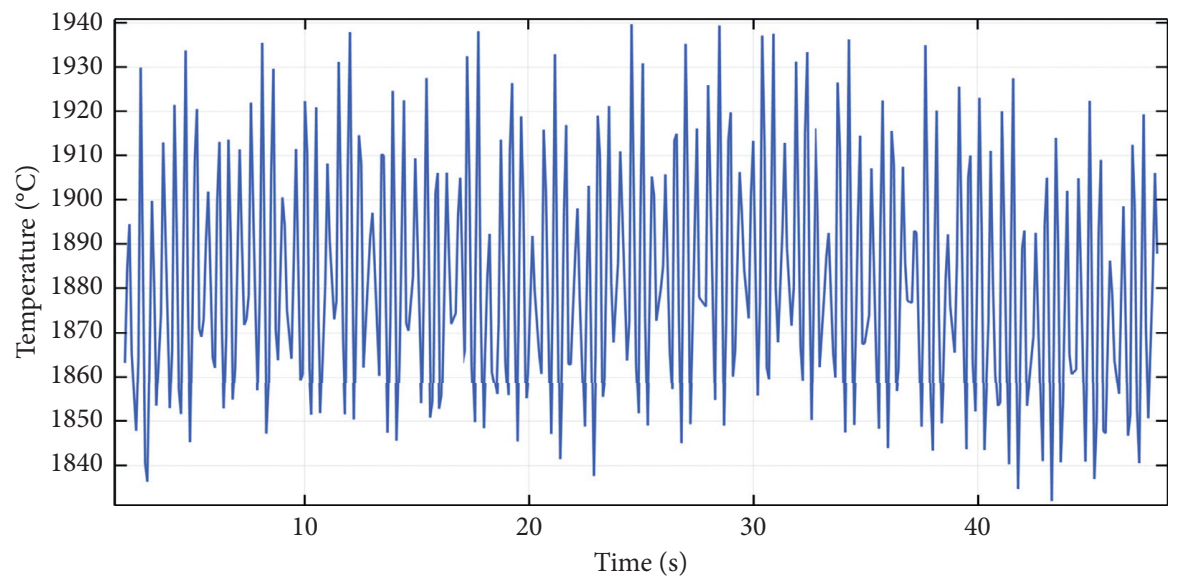

Figure 11: The distribution of the maximum temperature of molten pool with time (model 3 ).

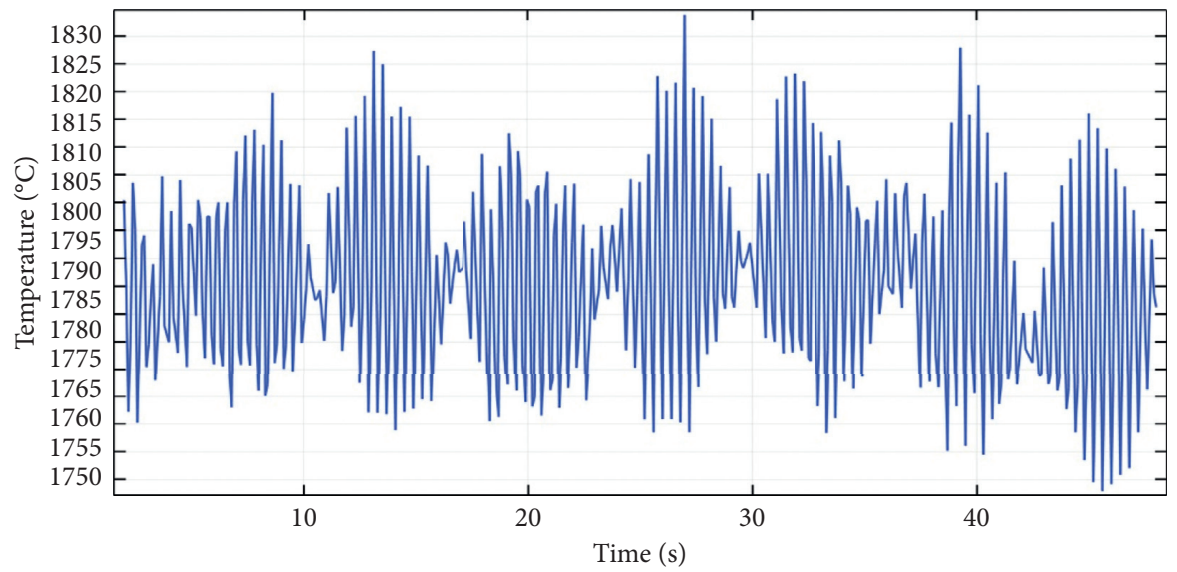

Figure 12: The distribution of the maximum temperature of molten pool with time (model 4).

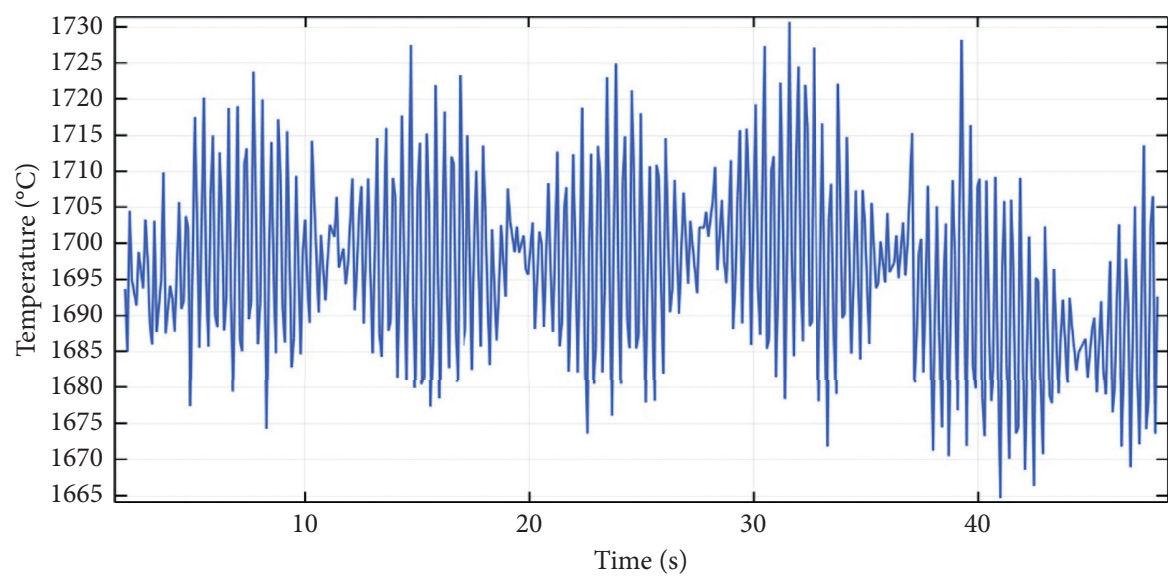

Figure 13: The distribution of the maximum temperature of molten pool with time (model 5). 


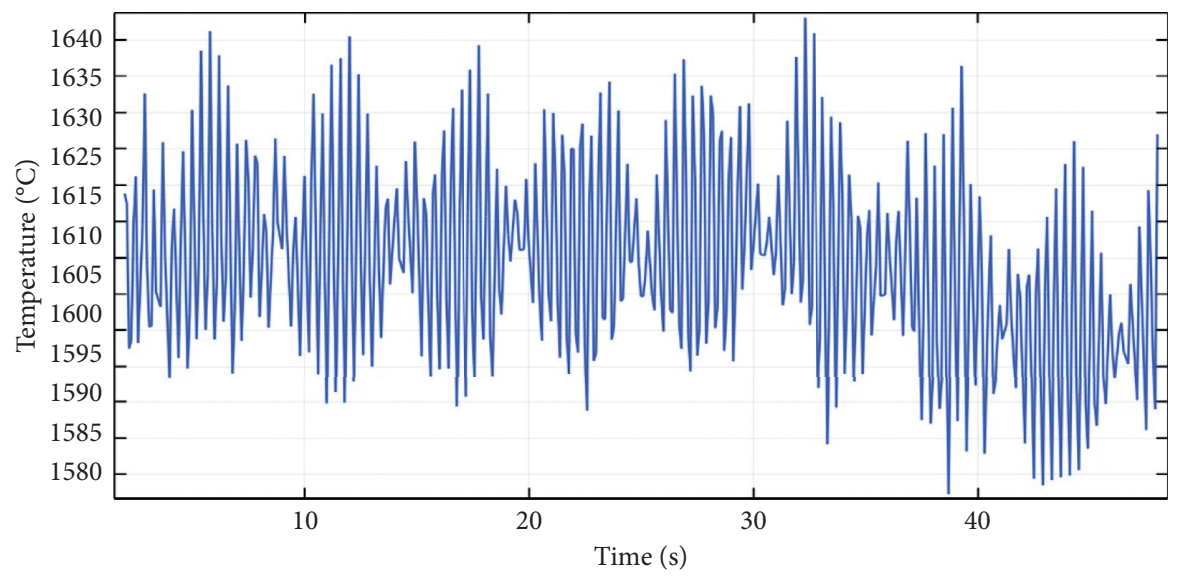

Figure 14: The distribution of the maximum temperature of molten pool with time (model 6).

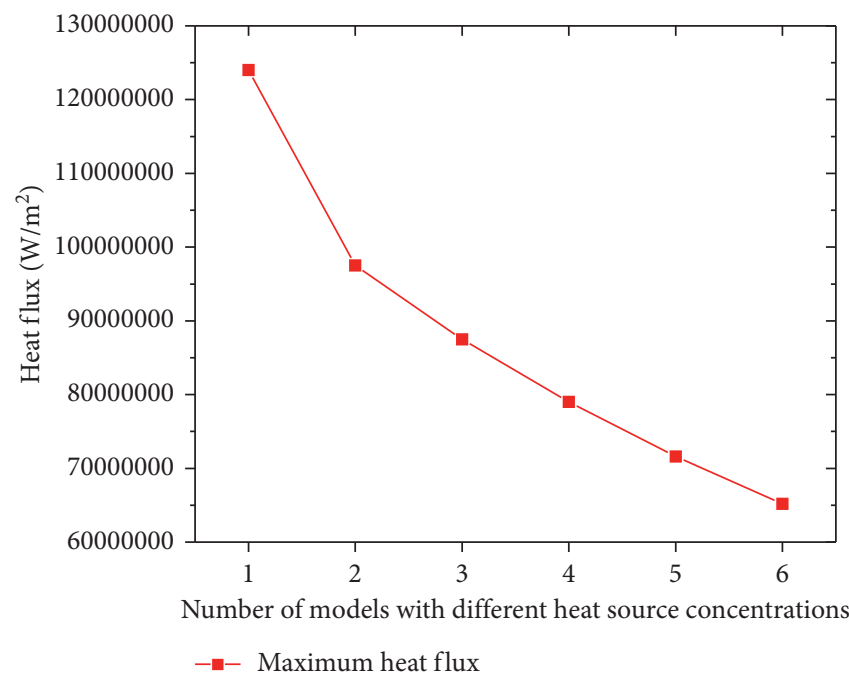

(a)

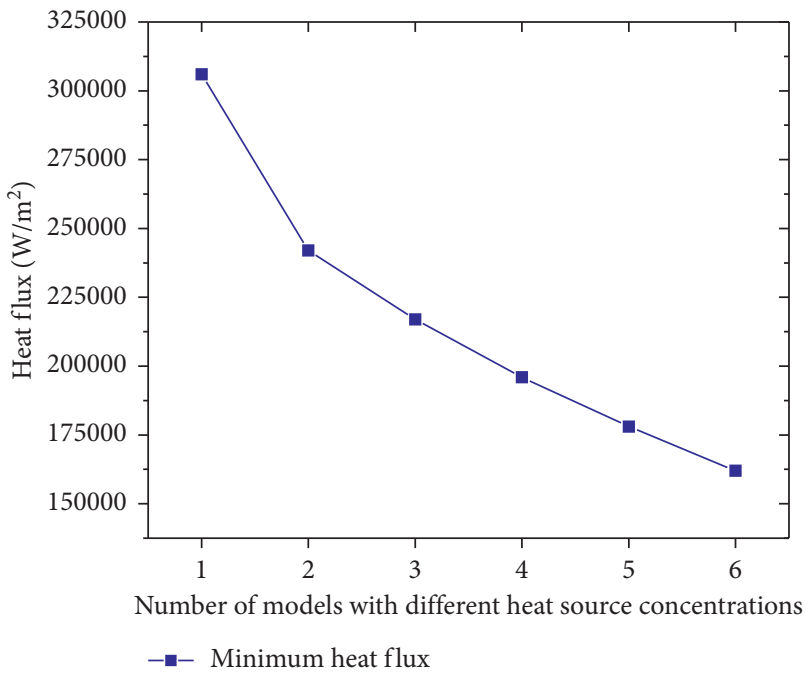

(b)

FIGURE 15: The change of maximum and minimum heat flow density. (a) The change of maximum heat flow density. (b) The change of minimum heat flow density.

energy loss in the actual process, model 3 has better agreement with the experimental data and can obtain the optimal numerical analysis results for following numerical analysis and further calculations.

\section{Heat Transfer Modeling and Numerical Analysis}

3.1. Calculation of Heat Input Range. In the previous study, we conducted a large number of experimental studies on the same size TC4 alloy and obtained the ideal welding parameters. The wire radius used in this study is $0.4 \mathrm{~mm}$, which is the same as the radius of the previous titanium alloy wire, so the wire is equal in volume at the same wire feed speed. Assume that the wire feed volume per unit time is $V$, according to the specific heat formula, the melting heat $Q$ required for wire feeding per unit time can be calculated as

$$
Q=C \cdot \rho V \cdot \Delta T
$$

During the welding process, the effective power of the heat source acts on the welding wire and the base metal, respectively. Take the average of the chemical composition of the two alloy wires and the base metal as the calculation basis. Then, we use JmatPro to calculate the average specific heat and density of the two alloys from $20^{\circ} \mathrm{C}$ to full liquid temperature $\left(1713^{\circ} \mathrm{C}\right.$ and $\left.1358^{\circ} \mathrm{C}\right)$, as is shown in the following: $\overline{C_{1}}=0.7811 \mathrm{~J} /(\mathrm{gK}), \overline{C_{2}}=0.7057 \mathrm{~J} /(\mathrm{gK}), \overline{\rho_{1}}=4306 \mathrm{~g} /$ $\mathrm{cm}^{3}$, and $\overline{\rho_{2}}=7956 \mathrm{~g} / \mathrm{cm}^{3} . \Delta T$ is the temperature difference from room temperature $20^{\circ} \mathrm{C}$ to the complete liquid temperature. The heat input ratio of the two alloys at the same wire feeding speed can be described as

$$
\frac{Q_{1}}{Q_{2}}=\frac{\overline{C_{1}} \cdot \overline{\rho_{1}} \cdot \Delta T_{1}}{\overline{C_{2}} \cdot \overline{\rho_{2}} \cdot \Delta T_{2}} \approx 0.758,
$$


TABLE 4: The average value of the maximum temperature of the molten pool.

\begin{tabular}{|c|c|c|c|c|c|}
\hline Model number & 2 & 3 & 4 & 5 & 6 \\
\hline AVG of the maximum temperature $\left({ }^{\circ} \mathrm{C}\right)$ & 2011 & 1880 & 1780 & 1691 & 1608 \\
\hline Difference from monitoring $\left({ }^{\circ} \mathrm{C}\right)$ & +210 & +80 & -21 & -110 & -272 \\
\hline
\end{tabular}

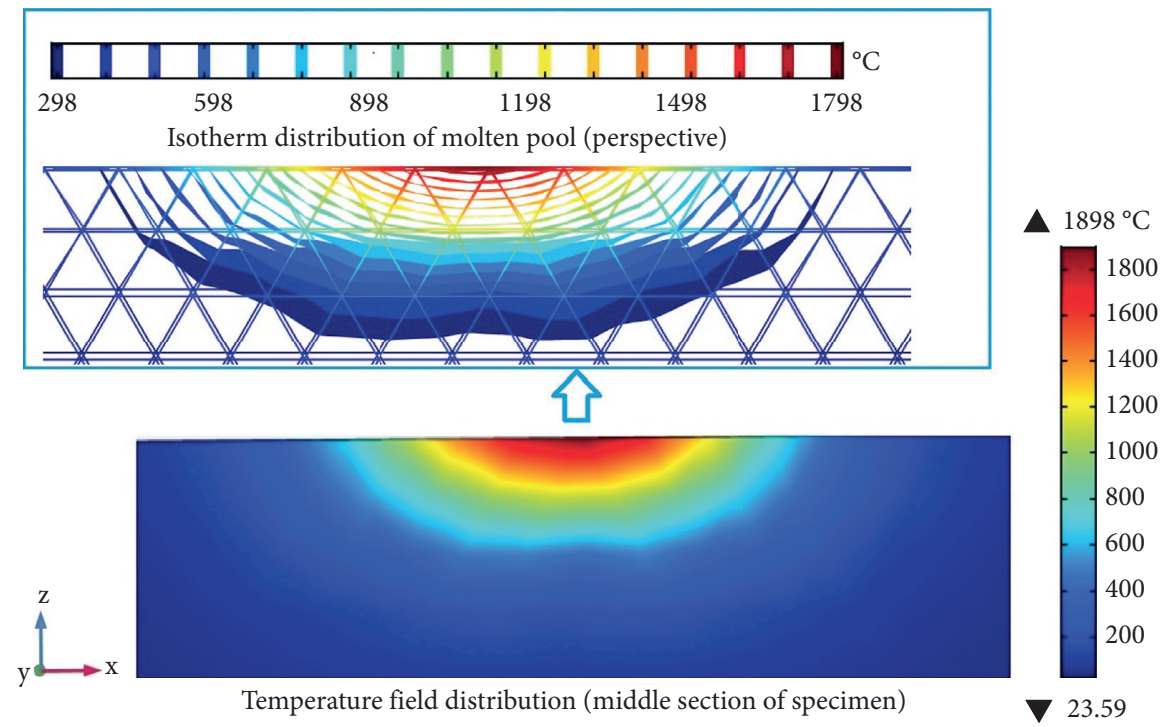

FIgURE 16: The isotherm and temperature distribution of molten pool in the center of the specimen.

where $Q_{1}$ and $Q_{2}$ are the heat required for TC4 welding wire and Inconel 718 welding wire in the same volume. According to the previous research results, the heat source power of TC4 alloy with the same radius of welding wire and the same dimension of test piece is about $330 \mathrm{~W}$. Considering the similar welding conditions, $330 \mathrm{~W}$ is used as the reference value of $Q_{1}$. Under the same welding parameters, the change of thermal conductivity with temperature may affect the distribution of heat input and the ratio coefficient is about $0.86 \sim 1.29$, so the value range of $Q_{2}$ is about 374 561 W.

3.2. Heat Transfer Calculations under Different Heat Inputs. Basing on the parameters of model 3, according to the range of $Q_{2}$ obtained by equation (15), the heat source power is set to $375 \mathrm{~W}, 431 \mathrm{~W}, 487 \mathrm{~W}, 521 \mathrm{~W}$, and $555 \mathrm{~W}$ to analyze the heat transfer model. Focusing on the moment when the heat source moves to the middle of the test piece, the surface temperature distribution of the molten pool is shown in Figure 17. After calculation, the corresponding maximum temperature of the molten pool is shown in Table 5 .

It is shown that when the heat source power is above $487 \mathrm{~W}$, the maximum temperature of the molten pool is greater than $2527^{\circ} \mathrm{C}$, reaching the boiling point temperature of some metal components, which will affect the metal composition of the final weld zone. Meanwhile, from the temperature distribution chart, when the heat input is above $487 \mathrm{~W}$, the size of the molten pool is larger, which will increase the cooling time of the molten pool. In addition, the penetration of different heat inputs of different wire feed speeds will also affect the weld quality.
3.3. Mathematical Model and Solutions of Different Surfacing Heights. After using the MPAW automatic welding system for surfacing, the cross section profile of the weld zone and base metal is as shown in Figure 7. Due to the uniform heat input of the MPAW automatic welding machine, the crosssectional radius increases uniformly with the increase of the wire feeding speed, and the melted wire is welded on the upper surface of the base material to form an approximately circular cross section with a radius $r$. In Figure 18, $h$ is the height from the weld bead to the center of the weld zone and $w$ is the width of base metal.

In order to simulate the surfacing height accurately at different wire feeding speeds, then calculate the maximum temperature distribution of the weld bead. Assuming that there is no loss in the process of melting and cooling and according to the principle of mass conservation, the relationship between cross section radius and wire feeding speed $v_{1}$ can be deduced as follows:

$$
\left[\pi r^{2} \cdot \frac{360-2 \arcsin (w / 2 r)}{360}+\frac{w}{2} \cdot \sqrt{r^{2}-\left(\frac{w}{2}\right)^{2}}\right] \cdot L=\pi R^{2} \cdot \frac{L}{v_{1}} \cdot v_{2}
$$

The thickness of the test piece is known as $w=1 \mathrm{~mm}$; the wire radius is known as $R=0.4 \mathrm{~mm}$; and the welding speed is known as $v_{1}=1.27 \mathrm{~mm} / \mathrm{s}(3 \mathrm{in} / \mathrm{min})$. The wire feeding speed $v_{2}$ is set to $1.27 \mathrm{~mm} / \mathrm{s}(3 \mathrm{in} / \mathrm{min}), 2.54 \mathrm{~mm} / \mathrm{s}(6 \mathrm{in} / \mathrm{min})$, $3.39 \mathrm{~mm} / \mathrm{s}(8 \mathrm{in} / \mathrm{min})$, and $4.24 \mathrm{~mm} / \mathrm{s}(10 \mathrm{in} / \mathrm{min})$, so

$$
\frac{v_{2}}{v_{1}}=\left[\frac{3}{3}, \frac{6}{3}, \frac{8}{3}, \frac{10}{3}\right]
$$


Let $r$ be an independent variable, that is, an iterative variable. Because of the difficulty in derivation, equation (29) can be converted to the following equation:

$$
r^{2}=\left\{\pi R^{2} \cdot \frac{v_{2}}{v_{1}}-\left[\pi r^{2} \cdot \frac{360-2 \arcsin (w / 2 r)}{360}\right]\right\}^{2} \cdot\left(\frac{2}{w}\right)^{2}+\left(\frac{w}{2}\right)^{2}
$$

Finding the first derivative of both ends of equation (31) is as follows:

$$
\begin{aligned}
r= & \left(\frac{2}{w}\right)^{2} \cdot\left\{\pi R^{2} \cdot \frac{v_{2}}{v_{1}}-\left[\pi r^{2} \cdot \frac{360-2 \arcsin (w / 2 r)}{360}\right]\right\} \\
& \cdot\left[-2 \pi r+\frac{\pi}{90} r \cdot \arcsin \left(\frac{w}{2 r}\right)-\frac{\pi w}{360} \cdot \frac{1}{\sqrt{1-(w / 2 r)^{2}}}\right] .
\end{aligned}
$$

Also, make

$$
\begin{aligned}
\varphi(r)= & \left(\frac{2}{w}\right)^{2} \cdot\left\{\pi R^{2} \cdot \frac{v_{2}}{v_{1}}-\left[\pi r^{2} \cdot \frac{360-2 \arcsin (w / 2 r)}{360}\right]\right\} \\
& \cdot\left[-2 \pi r+\frac{\pi}{90} r \cdot \arcsin \left(\frac{w}{2 r}\right)-\frac{\pi w}{360} \cdot \frac{1}{\sqrt{1-(w / 2 r)^{2}}}\right] \\
= & \left(\frac{2}{w}\right)^{2} \cdot \text { (1) (2) }
\end{aligned}
$$

Then, getting the first derivative for $r$ of equation (33) is as follows:

$$
\varphi^{\prime}(r)=\left(\frac{2}{w}\right)^{2} \cdot(2) \cdot(2)+\left(\frac{2}{w}\right)^{2} \cdot(1) \cdot\left\{-2 \pi+\frac{\pi}{90} \arcsin \left(\frac{w}{2 r}\right)-\frac{\pi w}{180} \cdot \frac{1}{\sqrt{1-(w / 2 r)^{2}} \cdot r}+\frac{\pi w^{3}}{1440} \cdot \frac{1}{\left[1-(w / 2 r)^{2}\right]^{-(3 / 2)} \cdot r^{3}}\right\}
$$

Selecting $r=r_{0}$ to substitute Newton iteration formula, the calculation steps are shown in Figure 19, where $\varepsilon$ is the required accuracy.

The surfacing height $H_{1}$ can be expressed as

$$
H_{1}=r+h=r+\sqrt{r^{2}-\left(\frac{w}{2}\right)^{2}}
$$

After calculation, the results obtained by the Newton iteration method are shown in Table 6.

\subsection{Maximum Temperature Calculations of the Weld Bead} Section. According to the calculation results of Table 4, surfacing height is lower at $3 \mathrm{in} / \mathrm{min}$ of wire feeding which will result in lower repair efficiency, and it is higher at $10 \mathrm{in} /$ min which will result in a lower cooling rate of the molten pool. So, select wire feeding speed of $2.54 \mathrm{~mm} / \mathrm{s}(6 \mathrm{in} / \mathrm{min}$, with $H=1.04 \mathrm{~mm})$ and $3.39 \mathrm{~mm} / \mathrm{s} \quad(8 \mathrm{in} / \mathrm{min}$, with $H=1.19 \mathrm{~mm}$ ) for simulation in the following study.

The first 0.2 seconds and the last 0.2 seconds are the arcstarting and arc-closing time, respectively, and the temperature fluctuation is large, which is not taken into account during the analysis. According to the calculation results of $0.2 \sim 49.8 \mathrm{~s}$ as shown in Figure 20, when the wire feeding speed is $8 \mathrm{in} / \mathrm{min}$ and power above $521 \mathrm{~W}$, the maximum temperature of the weld bead section is obviously higher than the melting temperature. When the power of the heat source is $487 \mathrm{~W}$, the mean value of maximum temperature at different times of the weld bead section is $1461.8^{\circ} \mathrm{C}$, which is higher than the melting temperature of $103^{\circ} \mathrm{C}$. When the power is $431 \mathrm{~W}$, the maximum temperature of the weld fluctuates along the melting temperature line; the mean value is $1361.7^{\circ} \mathrm{C}$, which is the closest to the melting temperature of $1358^{\circ} \mathrm{C}$. When the power is $375 \mathrm{~W}$, the mean value is $1236.7^{\circ} \mathrm{C}$, which is lower than the melting temperature of $122^{\circ} \mathrm{C}$. It may cause the metal of the weld bead not to melt completely. From the point of view of temperature fluctuation, under the heat input conditions of $487 \mathrm{~W}, 521 \mathrm{~W}$, and $555 \mathrm{~W}$, the temperature stability of the molten pool is poor, and the temperature curves fluctuate greatly and show a trend of high-temperature fluctuation after $35 \mathrm{~s}$. Under the heat input of $375 \mathrm{~W}$ and $431 \mathrm{~W}$, the temperature of the molten pool fluctuates slightly; although their temperature will fluctuate upward after 35 seconds, the fluctuation range is obviously smaller than that of the heat input power over $487 \mathrm{~W}$.

As shown in Figure 21, when the wire feeding speed is $6 \mathrm{in} / \mathrm{min}$ and heat source power is $487 \sim 555 \mathrm{~W}$, the maximum temperature range of the weld bead section can reach $1530-1926^{\circ} \mathrm{C}$, which exceeds the melting temperature more, and the heat input is larger. It can be speculated that the high-temperature residence time of the molten pool lasts longer, which can cause a longer cooling time of the molten pool. This phenomenon may produce more element segregation and reduce the mechanics of the weld zone. When the heat input is $375 \mathrm{~W}$, the mean value of maximum temperature at different times of the bead section is $1328^{\circ} \mathrm{C}$, which is close to the melting temperature. When the heat input is $431 \mathrm{~W}$, the mean value is $1464.2^{\circ} \mathrm{C}$, which is higher than the melting temperature of about $106^{\circ} \mathrm{C}$. From the point of view of temperature fluctuation, the heat input above $487 \mathrm{~W}$ will still produce a larger temperature fluctuation in the molten pool, especially after 35 seconds. The temperature will rise and the fluctuation range and fluctuation frequency are larger. At $375 \mathrm{~W}$ and $431 \mathrm{~W}$, the temperature fluctuation amplitude and fluctuation frequency are better than those of the previous heat input parameters. 


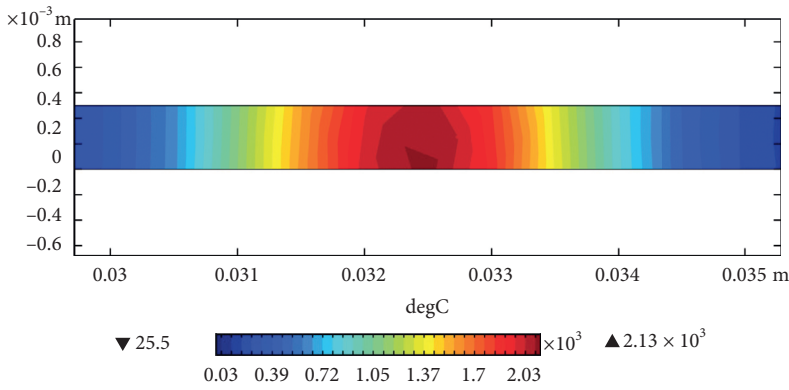

(a)

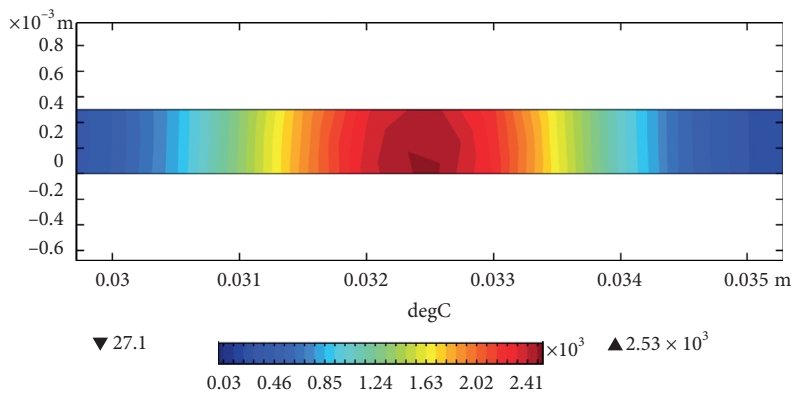

(c)

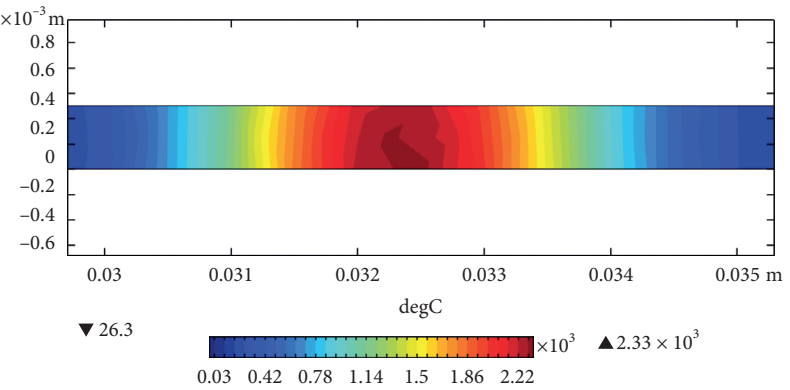

(b)

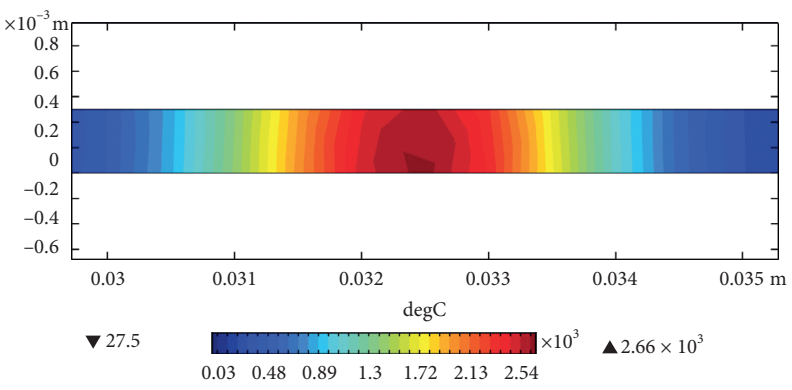

(d)

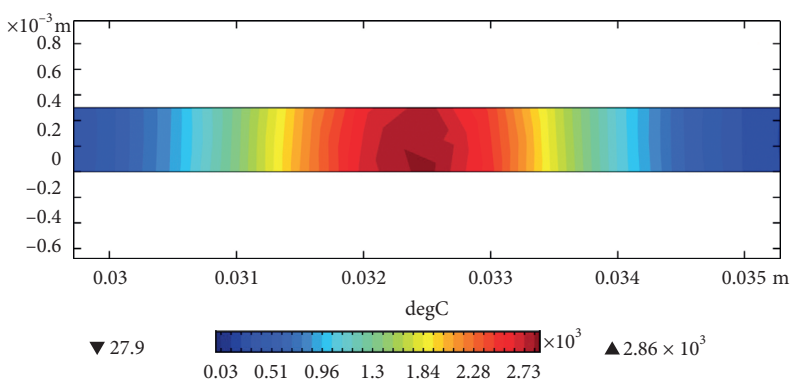

(e)

FIGURE 17: Temperature distribution of the molten pool under different heat inputs when the heat source moves to the center of the test piece. (a) $375 \mathrm{~W}$. (b) $431 \mathrm{~W}$. (c) $487 \mathrm{~W}$. (d) $521 \mathrm{~W}$. (e) $555 \mathrm{~W}$.

TABle 5: Maximum temperature calculations of the molten pool under different powers.

\begin{tabular}{lccccc}
\hline & 1 & 2 & 3 & 5 & 5 \\
\hline Heat source power $(\mathrm{W})$ & 375 & 431 & 487 & 521 & 555 \\
Maximum temperature $\left({ }^{\circ} \mathrm{C}\right)$ & 2130.4 & 2331.5 & 2527.5 & 2663.9 & 2858 \\
\hline
\end{tabular}

\section{Experiment and Discussion}

4.1. Experimental Parameters and Equipment. The high heat input leads to the formation of a large melting pool and a large amount of liquid metal, and it submits the weld region to long-term thermal cycles with low cooling rates [4]. For the welding of superalloy, the heat input should reduce as much as possible to achieve better weld quality under the condition of satisfying welding power. According to the maximum temperature distribution curves of Figures 9 and 10 , the heat input of $375 \mathrm{~W}$ and $431 \mathrm{~W}$ with small fluctuation of pool temperature was selected as experimental power. Welding experiments were carried out at wire feeding rates of $2.54 \mathrm{~mm} / \mathrm{s} \quad(6 \mathrm{in} / \mathrm{min})$ and $3.39 \mathrm{~mm} / \mathrm{s} \quad(8 \mathrm{in} / \mathrm{min})$, respectively, and the heat source moving speed of $1.27 \mathrm{~mm} / \mathrm{s}$ ( $3 \mathrm{in} / \mathrm{min})$. According to the base voltage value of our previous study [31] and the results of welding experiments on Inconel 718 plates, the voltage values of this experiment are set to $15 \mathrm{~V}$ and $15.4 \mathrm{~V}$. Correspondingly, the current values calculated by the heat source power are $25 \mathrm{~A}$ and $28 \mathrm{~A}$. The main experimental parameters are as shown in Table 7.

The experimental equipment is shown in Figure 22. The welding experiments were carried out by LAWS500 MPAW automatic machine. The microstructures and energy spectrum analysis of the weld zone were tested by Leica DM2700M optical microscope and ZEISS Sigma 300 SEM equipped with Oxford X-MAX EDS. The above experiment follows the standard of the test method for the 


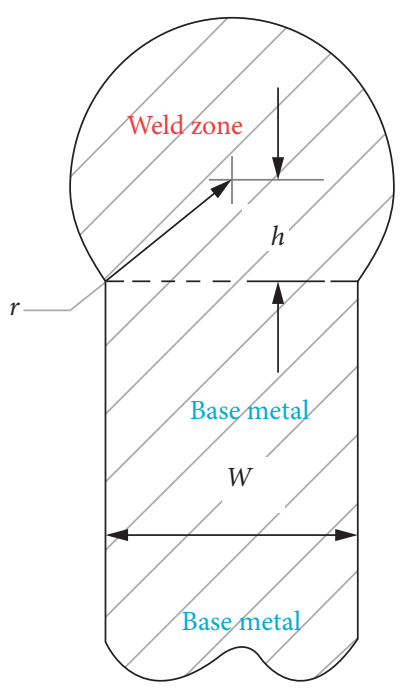

Figure 18: Cross section morphology after surfacing.

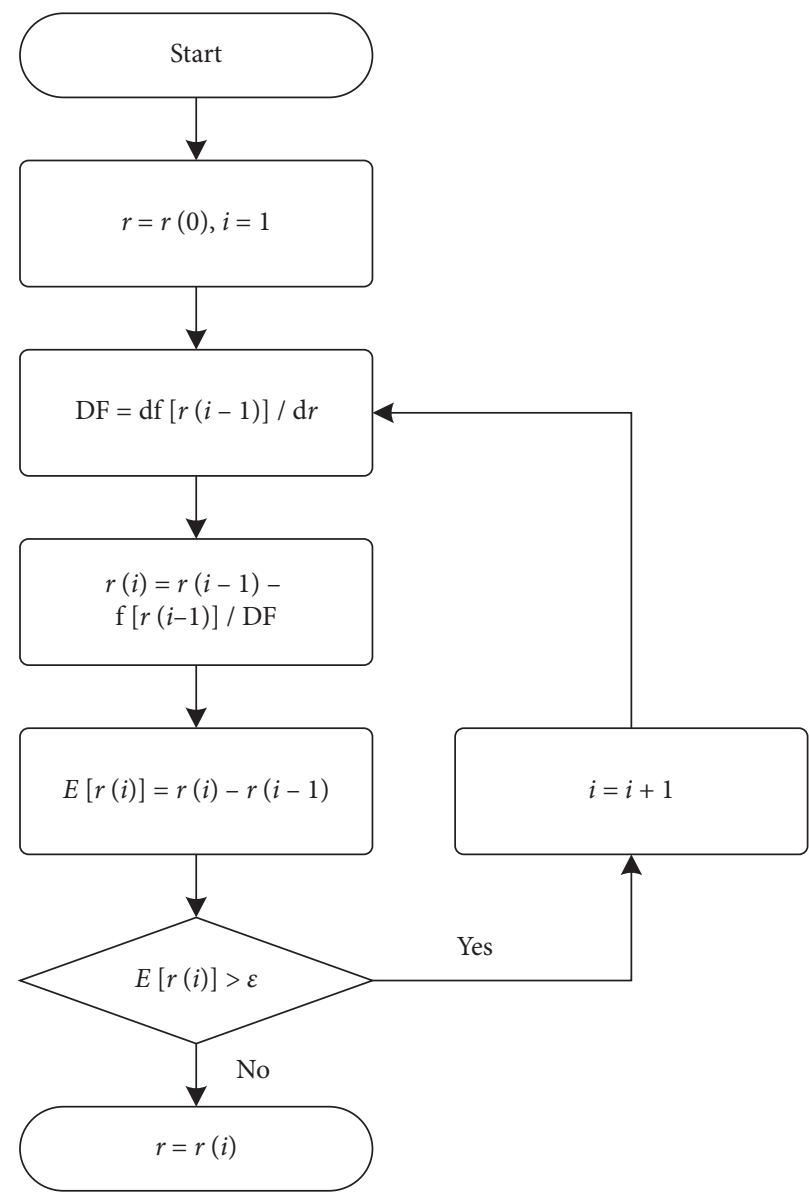

Figure 19: Newton iteration calculation steps by MATLAB.

TABLE 6: Results of different wire feed speeds.

\begin{tabular}{lcccc}
\hline$\left(v_{2} / v_{1}\right)$ & $(3 / 3)$ & $(6 / 3)$ & $(8 / 3)$ & $(10 / 3)$ \\
\hline Initial value & 1 & 1 & 1 & 1 \\
$r_{i}(\mathrm{~mm})$ & $5.523828 \times 10^{-1}$ & $6.410283 \times 10^{-1}$ & $7.003568 \times 10^{-1}$ & $7.589380 \times 10^{-1}$ \\
$\varepsilon$ & $1 \times 10^{-10}$ & $1 \times 10^{-10}$ & $1 \times 10^{-10}$ & $1 \times 10^{-10}$ \\
Number of iterations & 32 & 32 & 31 & 30 \\
Previous error & $9.824941 \times 10^{-11}$ & $5.845890 \times 10^{-11}$ & $7.737799 \times 10^{-11}$ & $9.592882 \times 10^{-11}$ \\
$H_{1}(\mathrm{~mm})$ & 0.78 & 1.04 & 1.19 & 1.33 \\
\hline
\end{tabular}




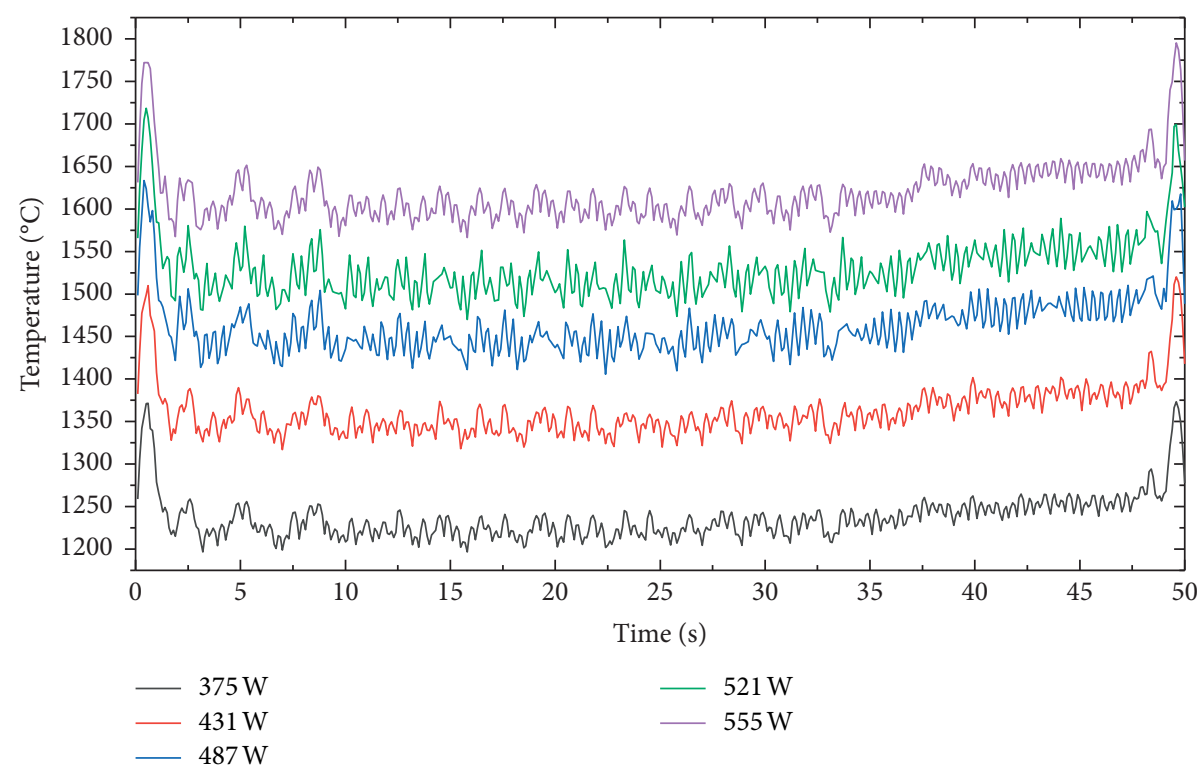

FIgURe 20: Change of maximum temperature of weld bead section with time (wire feeding speed is $3.39 \mathrm{~mm} / \mathrm{s}$ ).

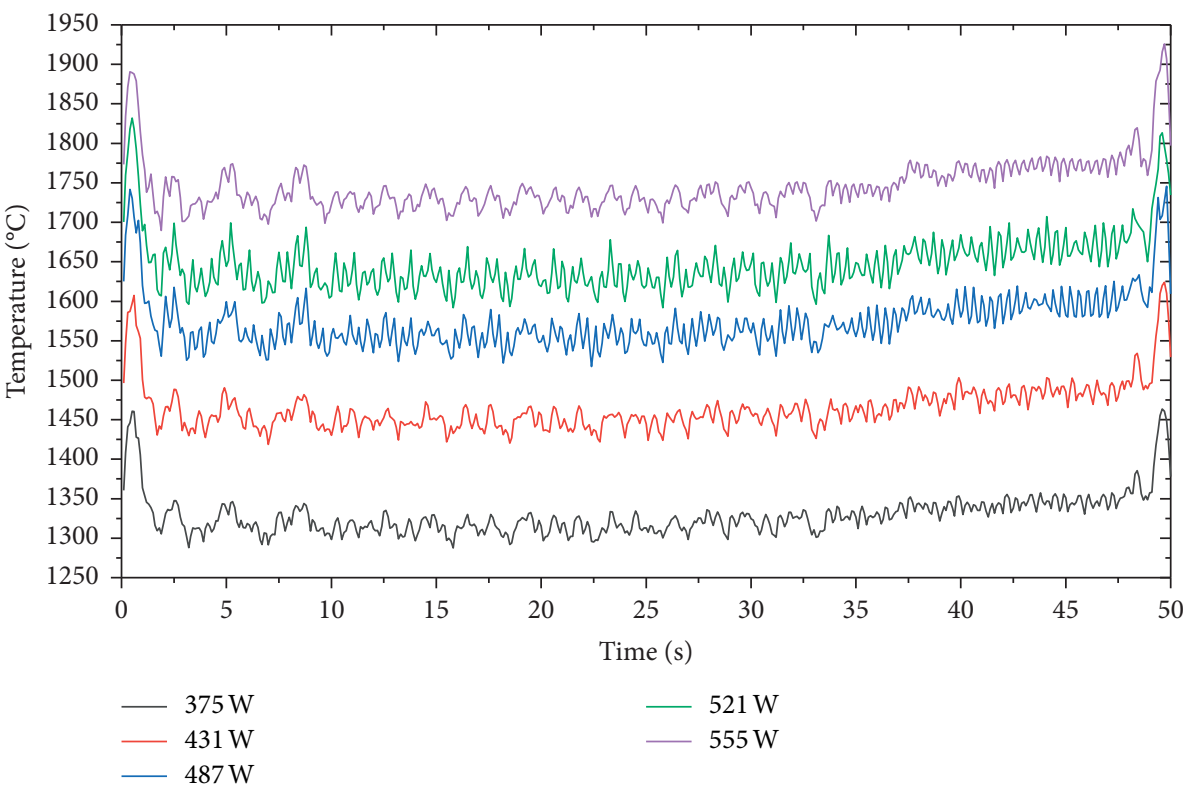

FIGURE 21: Change of maximum temperature of weld bead section with time (wire feeding speed is $2.54 \mathrm{~mm} / \mathrm{s}$ ).

TABLE 7: Main experimental parameters.

\begin{tabular}{lcccc}
\hline Expt. no. Current (A) & Voltage (V) & Wire speed & $\begin{array}{c}\text { Welding } \\
\text { speed }\end{array}$ \\
\hline 1 & 25 & 15 & $3.39 \mathrm{~mm} / \mathrm{s}$ & $1.27 \mathrm{~mm} / \mathrm{s}$ \\
2 & 25 & 15 & $2.54 \mathrm{~mm} / \mathrm{s}$ & $1.27 \mathrm{~mm} / \mathrm{s}$ \\
3 & 28 & 15.4 & $3.39 \mathrm{~mm} / \mathrm{s}$ & $1.27 \mathrm{~mm} / \mathrm{s}$ \\
4 & 28 & 15.4 & $2.54 \mathrm{~mm} / \mathrm{s}$ & $1.27 \mathrm{~mm} / \mathrm{s}$ \\
\hline
\end{tabular}

microstructure of superalloys (Standard code: GB/T 1499.4), the test method for metallographic microstructure (standard code: GB/T 13298) and the detection method for chemical composition and surface morphology (standard code: GB/T 17359). The hardness of the weld zone was tested by
Matsuzawa MMT-X microhardness tester. The normal force loading range of the Vickers hardness device is $1 \mathrm{gf}$ to 2000 gf, and the indentation measurement accuracy can reach $0.01 \mu \mathrm{m}$. It can accurately measure the hardness of thin sheet, electroplated coating, round shaft, and microworkpiece. The standard of Vickers hardness test follows Vickers hardness test method of metallic materials (Standard code: GB/T 4340.1-2009).

\section{Results and Discussion}

The results of optical microscopy observation in the weld zone under the parameter of Expt. 1 are as shown in Figure 23. The corrosive agent was $1 \mathrm{~g} \mathrm{CuCl}_{2}+20 \mathrm{ml}$ 


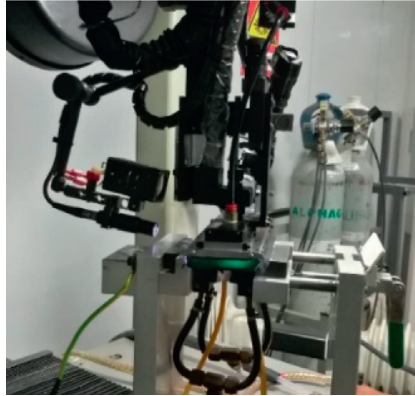

(a)

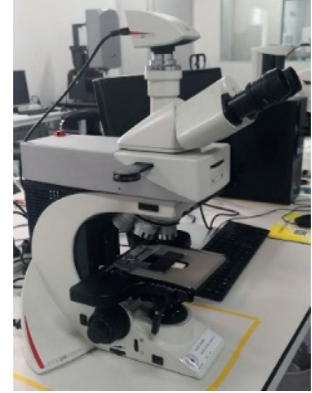

(b)

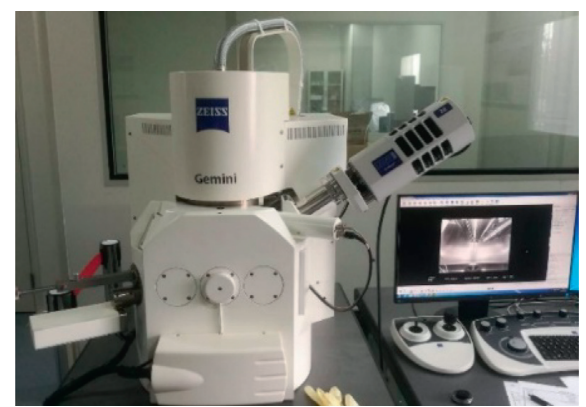

(c)

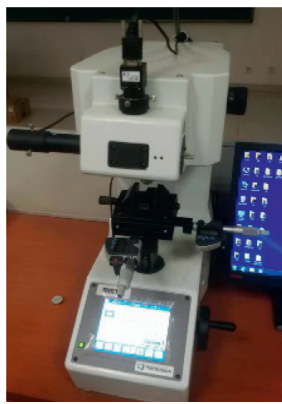

(d)

FIgURE 22: The experimental equipment. (a) LAWS500 MPAW automatic machine. (b) Leica DM2700M. (c) ZEISS Sigma 300 SEM. (d) Matsuzawa MMT-X.

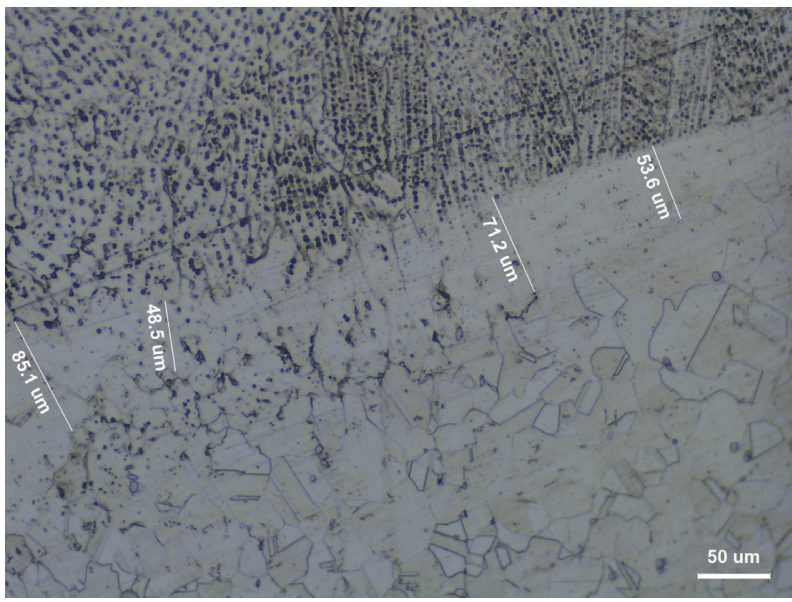

Figure 23: The microstructure of the weld zone (Expt. 1).

$\mathrm{HCl}+20 \mathrm{ml}$ ethanol. When the power of the heat source is $375 \mathrm{~W}$ and the wire feeding speed was $3.39 \mathrm{~mm} / \mathrm{s}(8 \mathrm{in} / \mathrm{min})$, a wide white band appeared in the weld zone. As shown in Figure 24, the energy spectrum analysis shows that the content of $\mathrm{Ni}$ in this area is high (about 64.5\% 66.1\%) while that of $\mathrm{Nb}$ is low (about 2.41\% 2.64\%).

By detecting the precipitated particles, the results are shown in Figure 25. The results show that the content of $\mathrm{Nb}$ in the precipitated particles is very high. The precipitated particles are mainly $\mathrm{C}$ and $\mathrm{Nb}$ compounds [26]. The occurrence of undesirable element segregation in the white region results in the generation of segregation regions of high $\mathrm{Ni}$ and low $\mathrm{Nb}$, the content of $\mathrm{Nb}$ in this region is low. The low content of $\mathrm{Nb}$ in this region will reduce the strengthening phase of the formation of tetragonal $\mathrm{Ni}_{3} \mathrm{Nb}$ $\left(\gamma^{\prime \prime}\right)$ and face-centered cubic $\mathrm{Ni}_{3}(\mathrm{Al}, \mathrm{Ti}, \mathrm{Nb})\left(\gamma^{\prime}\right)$, which in turn leads to poor mechanical properties of the weld. From the simulation data, the weld bead section temperature corresponding to Expt. 1 ranges from 1200 to $1300^{\circ} \mathrm{C}$, which is lower than the melting temperature. It can be inferred that the lower heat input makes the heat applied to the wire per unit time lower. It is the main reason for the white zone in the weld of the test piece of Expt. 1.

For further verification, the wire feeding speed was reduced to $2.54 \mathrm{~mm} / \mathrm{s}(6 \mathrm{in} / \mathrm{min})$ at $375 \mathrm{~W}$ (Expt. 2), and the metallographic structure under the light microscope is shown in Figure 26. After reducing the wire feeding speed, the width of the white segregation zone was reduced, and the corresponding simulation results show that the maximum temperature range of the weld bead section is $1300-1450^{\circ} \mathrm{C}$, which fluctuates up and down near the melting line. It shows that the temperature of the weld bead section rises, the heat applied to the welding wire increases per unit time, and the element segregation decreases, but the heat input is still insufficient. The simulation trend is consistent with the experimental results basically. If the wire feeding amount is continuously reduced, it is expected to be further decreased, but the wire feeding repair process may result in insufficient wire feeding and insufficient welding height, so the heat input of the Expt. 1 and 2 cannot meet the welding requirements.

In Expt. 3, the heat input was increased to $431 \mathrm{~W}$, and the wire feed speed was selected to $3.39 \mathrm{~mm} / \mathrm{s}(8 \mathrm{in} / \mathrm{min})$ first. The light microscope observation result in the weld zone is shown in Figure 27. After the increase of heat input, the microstructure of the weld zone was obviously improved. The segregation zone was obviously smaller comparing with Expt. 1 and 2. The energy spectrum analysis of the weld zone of Expt. 3 is shown in Figure 28. The energy spectrum 

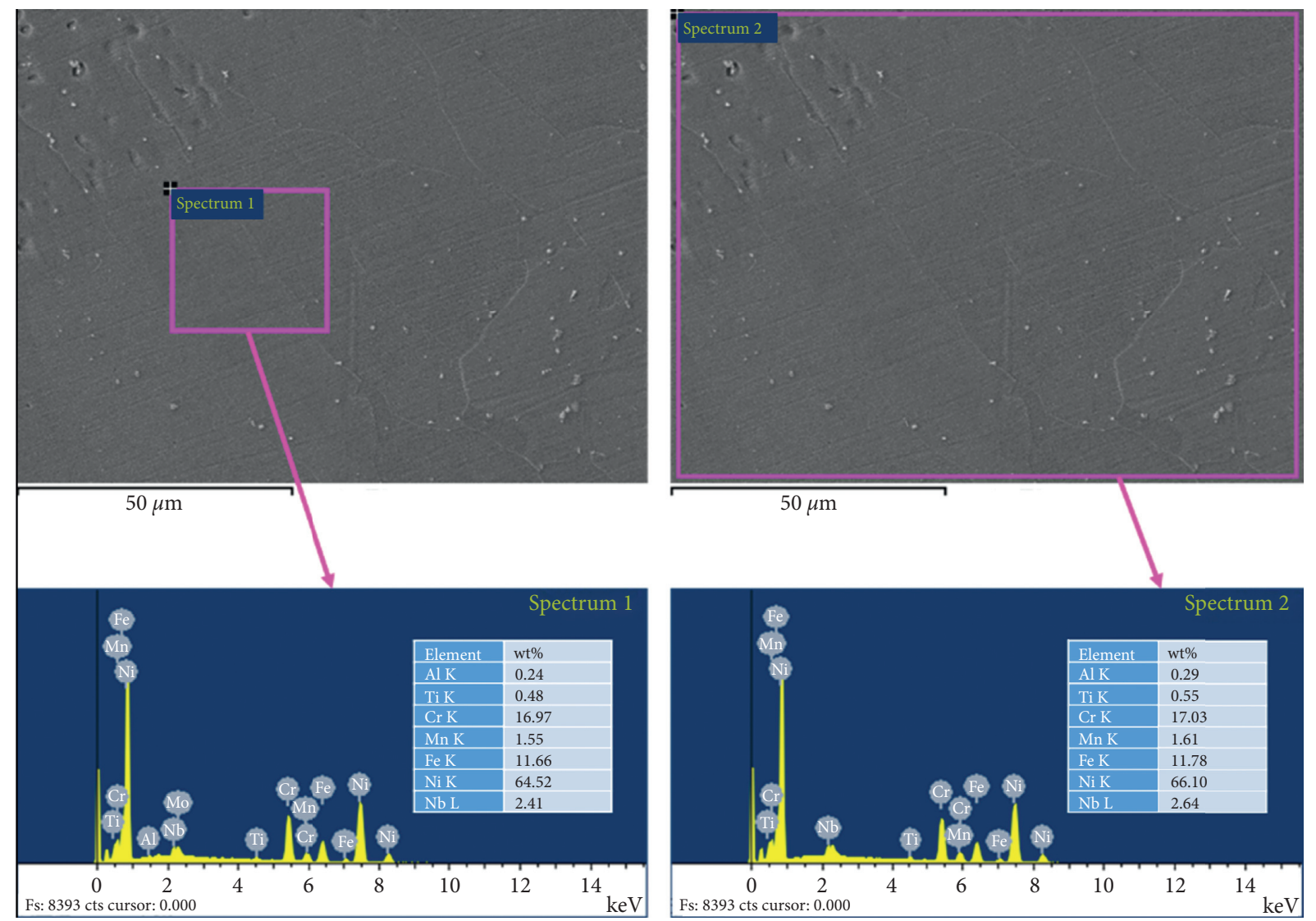

FIgURE 24: EDS of white banded structure in the weld zone (Expt. 1).
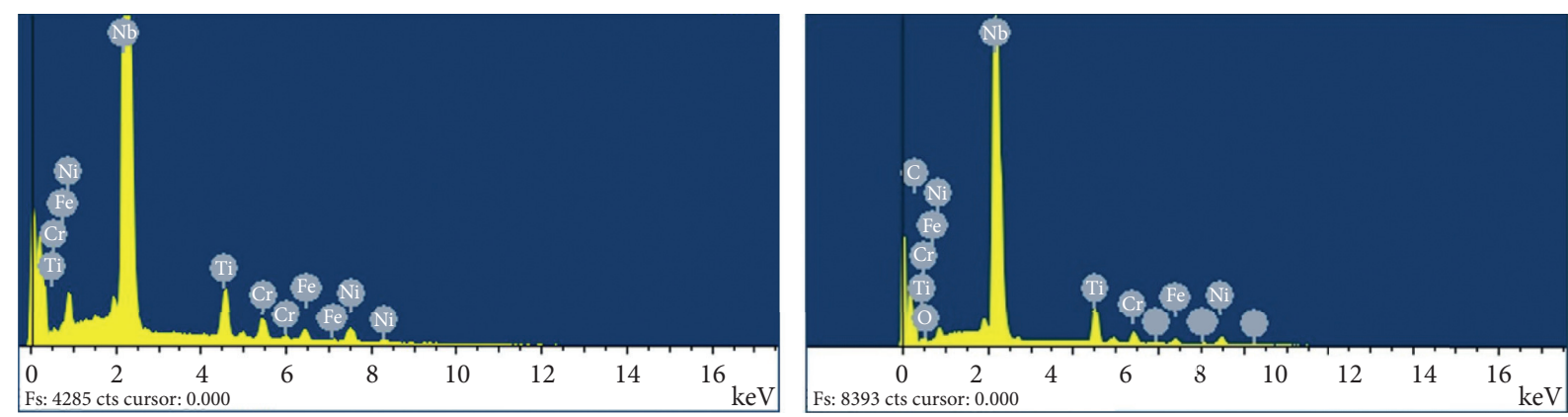

Figure 25: Energy spectrum analysis of precipitates (Expt. 1).

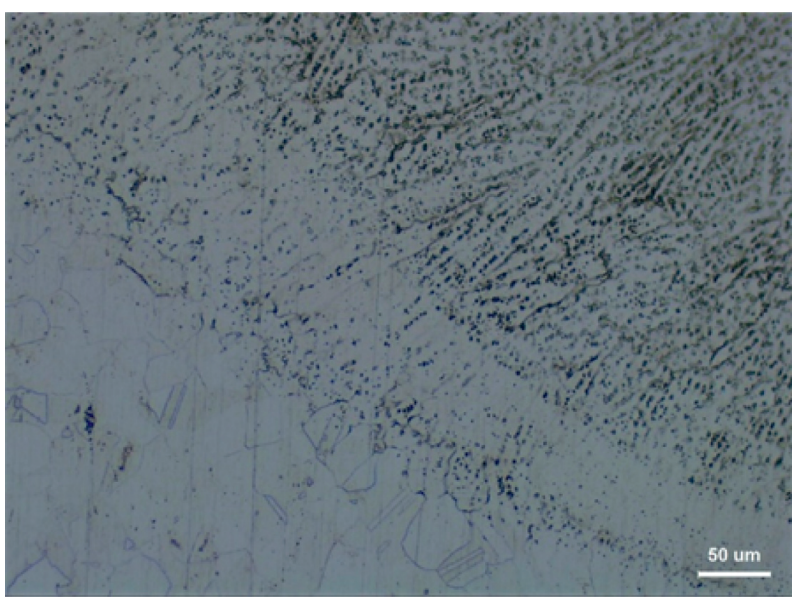

Figure 26: The microstructure of the weld zone (Expt .2). 


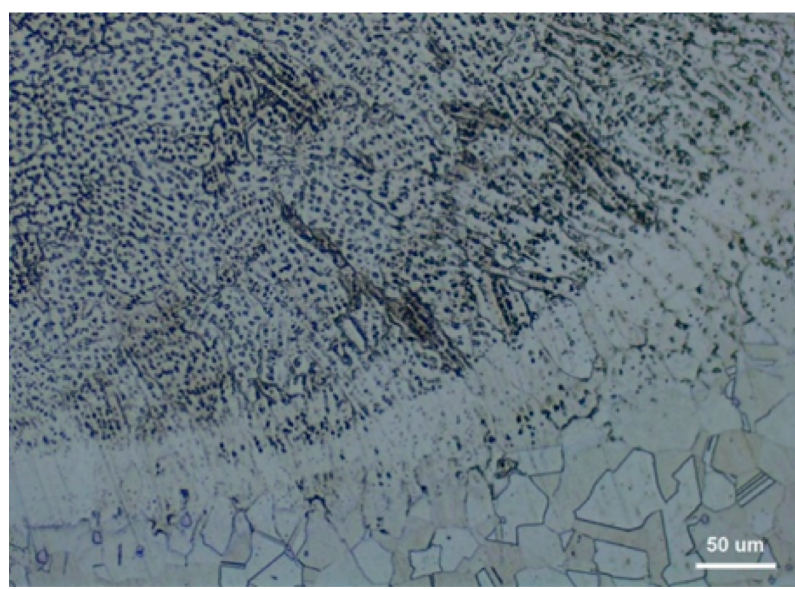

FIgURE 27: The microstructure of the weld zone (Expt. 3).
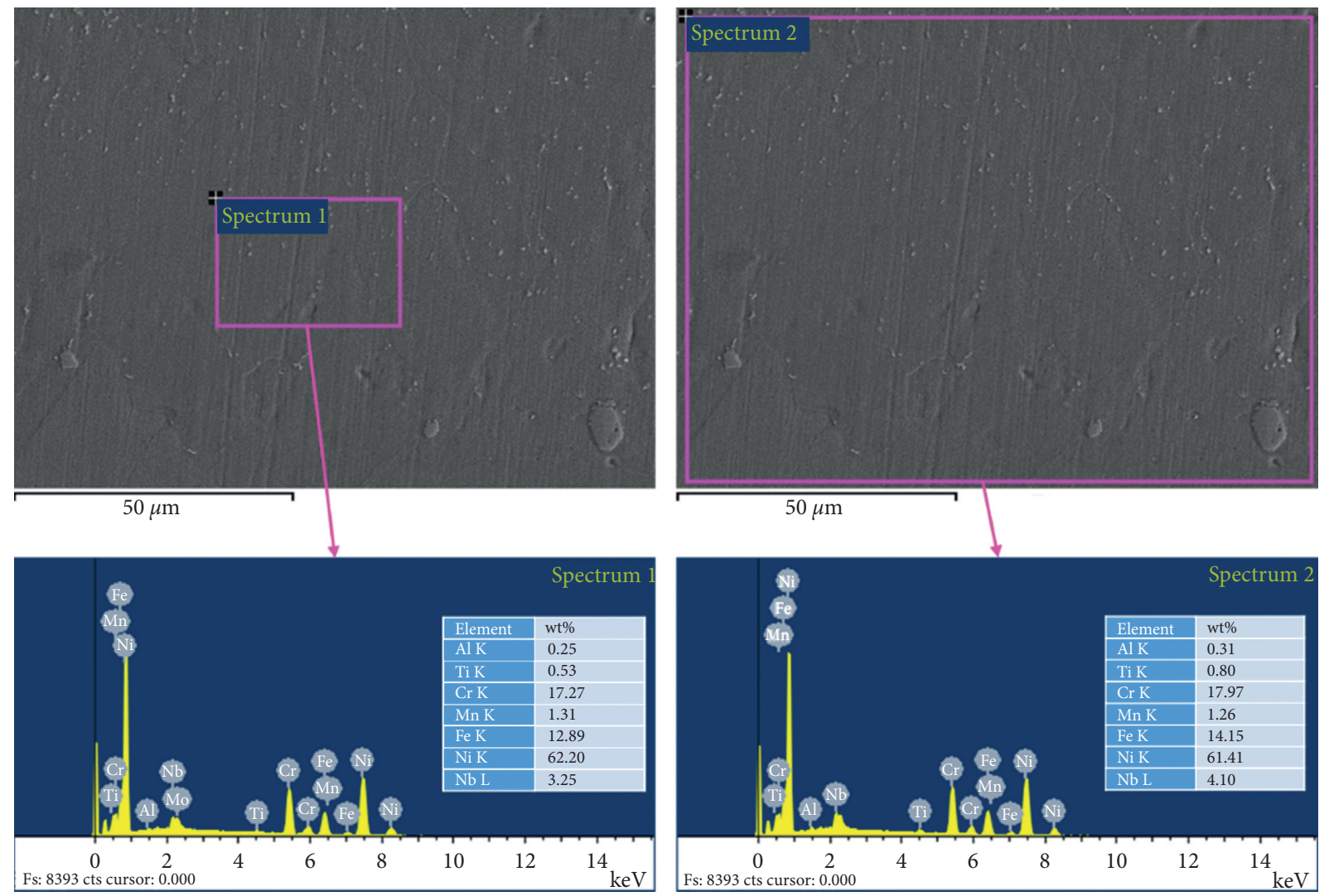

FIGURE 28: EDS of white banded structure in weld zone (Expt. 3).

analysis showed that the $\mathrm{Ni}$ content in the white band region had decreased (about 61.4 62.2\%), and the $\mathrm{Nb}$ content had increased (about 3.25 4.1\%). The simulation results corresponding to Expt. 3 show that the maximum temperature of the weld section is between 1325 and $1550^{\circ} \mathrm{C}$. Considering the heat loss during the welding process, the average temperature of the weld section may still be lower than the melting temperature, thus causing the segregation area to shrink but still exist.

In Expt. 4, the wire feeding speed was reduced to $2.54 \mathrm{~mm} / \mathrm{s}$ (6 in/min) under the heat source of $431 \mathrm{~W}$, and the results of light microscopy in the weld zone are as shown in Figure 29. The segregation phenomenon in the weld zone was obviously improved, and the segregation zone of high $\mathrm{Ni}$ and low $\mathrm{Nb}$ basically disappeared. The quality of the weld zone was significantly better than that of the previous experiments. The HDBSD test was performed on the microstructure of the weld zone, as shown in Figure 30. The results show that the precipitation of $\mathrm{Nb}$ is well distributed in the weld zone. It exhibits a diffuse distribution and does not reach the extent of forming a distinct chain of Laves phase $[23,34,35]$. The maximum temperature of the weld bead 


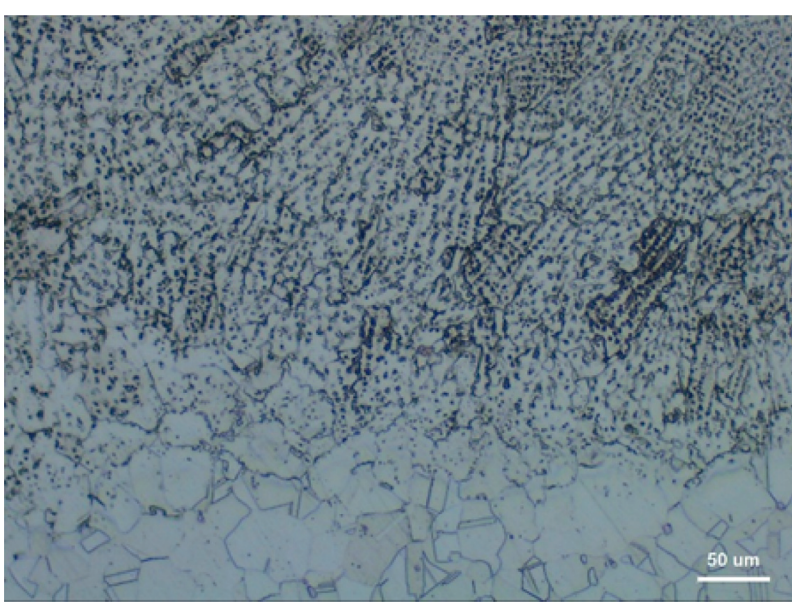

Figure 29: Microstructure of the weld zone (Exp. 4).

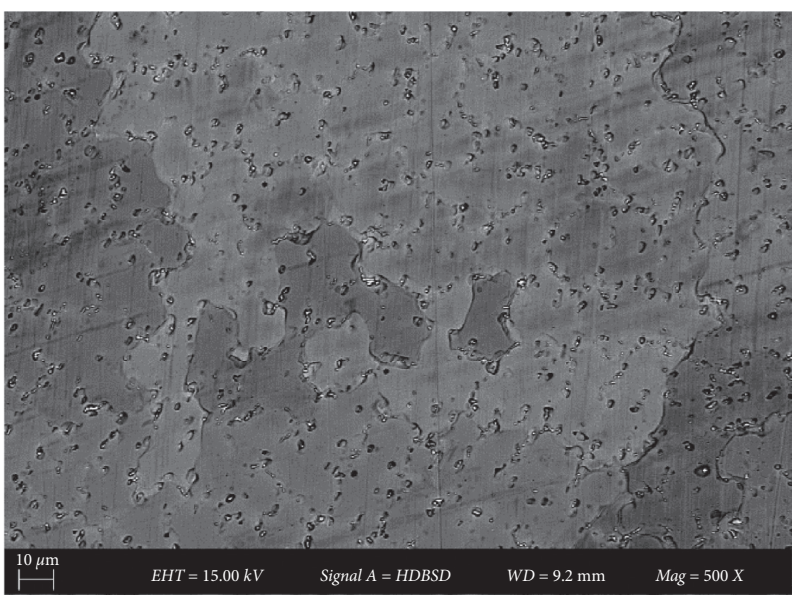

FIgUre 30: HBSD imaging of the weld zone (Exp. 4).

section corresponding to Expt. 4 is $1450 \sim 1600^{\circ} \mathrm{C}$. It is speculated that there may be a heat loss effect of about $100^{\circ} \mathrm{C}$ in the actual process.

Due to the small size of Inconel 718 alloy piece and surfacing zone, some mechanical properties are difficult to test. In this study, the quality of surfacing repair is mainly determined by the observation of microstructure morphology, composition analysis of G.P. zone, and test of microhardness. EDS analysis was performed on the G.P. zone of Expt. 4. The results are as shown in Figure 31 and Table 8 . It is shown that the average content of $\mathrm{Nb}$ in the G.P. zone is $4.2 \%$, and the precipitation of $\mathrm{Nb}$ is significantly reduced under the heat input condition of Expt. 4 . The $\mathrm{Nb}$ in the G.P. zone is as the content increases, this will increase the formation of the strengthening phase $\mathrm{Ni}_{3} \mathrm{Nb}\left(\gamma^{\prime \prime}\right)$ and $\mathrm{Ni}_{3}$ $(\mathrm{Al}, \mathrm{Ti}, \mathrm{Nb})\left(\gamma^{\prime}\right)$, thereby effectively improving the mechanical properties of the weld zone.

The Vickers hardness test was performed on the weld zone and the base metal of Expt. 4 using a Matsuzawa MMT$\mathrm{X}$ microhardness tester. Five points were evenly sampled vertically from the weld position for testing the hardness of the weld zone. Similarly, five points were vertically sampled from the base material down the weld position; the results are as shown in Table 9. The results show that the average Vickers hardness of the weld zone is close to that of the base metal, and the difference ratio is $1.66 \%$. For the $1 \mathrm{~mm}$ ultrathin Inconel 718 alloy, the welding parameters of Expt. 4 can achieve better first-stage welding quality.

From the comparison of experimental results and simulation trends, they are in good agreement. Under the condition of $375 \mathrm{~W}$ heat source power and $6 \sim 8 \mathrm{in} / \mathrm{min}$ wire feeding speed, although the temperature of molten pool reaches about $2130.4^{\circ} \mathrm{C}$, due to the effect of wire feeding speed on surfacing height, the maximum temperature of the weld bead section is lower than the optimum fusion temperature. Meantime, an unsatisfactory segregation zone appears in the weld zone, which will weaken the strengthening term. When the heat source power is $431 \mathrm{~W}$, the segregation zone decreases with the increase of heat input, and the maximum temperature of the weld cross section gradually reaches above the optimal fusion temperature. Under the parameters of Expt. 4, when the heat input is $431 \mathrm{~W}$ and the wire feeding speed is $6 \mathrm{in} / \mathrm{min}$, the weld bead reaches a better morphology and the weld zone achieves 


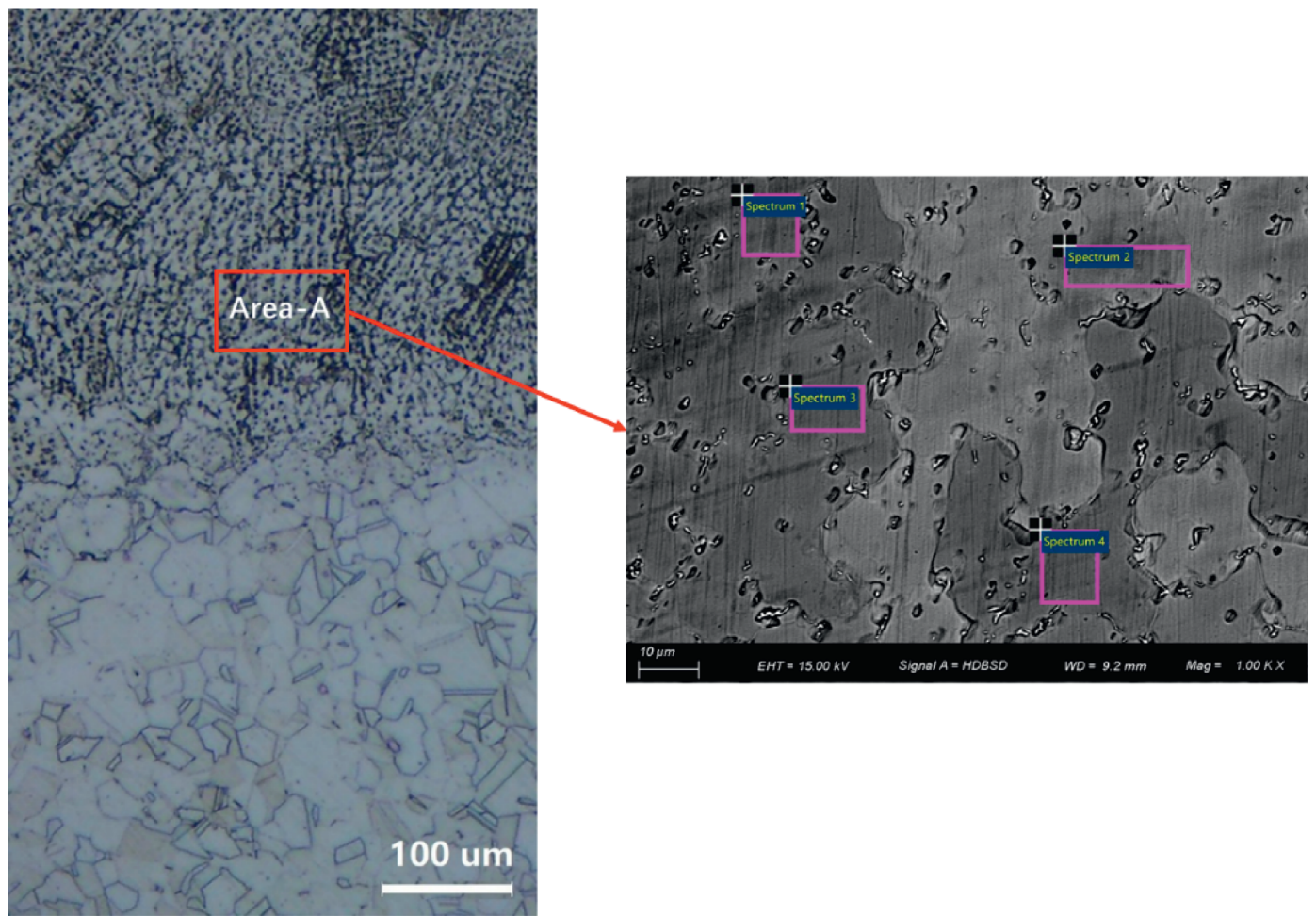

FIgURE 31: HDBS and EDS of the weld zone (Expt. 4).

TABLE 8: The chemical composition (wt.\%) of different GP zones (Expt. 4).

\begin{tabular}{lcccccccc}
\hline Element & $\begin{array}{c}\mathrm{Al} \\
\mathrm{K}\end{array}$ & $\begin{array}{c}\mathrm{Nb} \\
\mathrm{L}\end{array}$ & $\begin{array}{c}\mathrm{Mo} \\
\mathrm{L}\end{array}$ & $\begin{array}{c}\mathrm{Ti} \\
\mathrm{K}\end{array}$ & $\begin{array}{c}\mathrm{Cr} \\
\mathrm{K}\end{array}$ & $\begin{array}{c}\mathrm{Mn} \\
\mathrm{K}\end{array}$ & $\begin{array}{c}\mathrm{Fe} \\
\mathrm{K}\end{array}$ & $\begin{array}{c}\mathrm{Ni} \\
\mathrm{K}\end{array}$ \\
\hline $\begin{array}{l}\text { Spectrum } \\
1\end{array}$ & 0.73 & 4.23 & 2.44 & 0.9 & 18.15 & 0.71 & 18.49 & 54.35 \\
$\begin{array}{l}\text { Spectrum } \\
2\end{array}$ & 0.88 & 4.0 & 2.52 & 1.33 & 17.64 & 1.16 & 18.78 & 53.69 \\
$\begin{array}{l}\text { Spectrum } \\
3\end{array}$ & 0.6 & 4.38 & 2.79 & 1.09 & 18.14 & 0.65 & 18.36 & 53.99 \\
$\begin{array}{l}\text { Spectrum } \\
4\end{array}$ & 0.66 & 4.17 & 2.59 & 1.07 & 17.87 & 0.74 & 18.65 & 54.25 \\
Avg. 1-4 & 0.72 & 4.2 & 2.56 & 1.1 & 17.95 & 0.82 & 18.57 & 54.07 \\
\hline
\end{tabular}

TABLE 9: HV test results in different areas (HV0.1).

\begin{tabular}{lcccccc}
\hline Element & 1 & 2 & 3 & 4 & 5 & $\begin{array}{c}\text { Avg. } \\
1-5\end{array}$ \\
\hline $\begin{array}{l}\text { Weld } \\
\text { zone } \\
\text { Base } \\
\text { metal }\end{array}$ & 198.3 & 197.5 & 193.9 & 195.1 & 189.7 & 195.88 \\
& 206.7 & 199.7 & 194.2 & 193,7 & 195.7 & 199.08 \\
& $\begin{array}{c}\text { Difference ratio } \\
(\%)\end{array}$ & & & & & $1.66 \%$ \\
\hline
\end{tabular}

Vickers hardness similar to the base metal. The simulation model and calculation results are of positive significance for determining the ideal range of welding heat input parameters of aero ultrathin nickel-base blade.

There are some uncertain factors, which may influence the results and need to be further studied. The fixture assembly gaps are the gaps between the copper blocks, the gaps between copper blocks and clamping structure, and the gaps between copper blocks and blade. The size of these gaps is different from the assumptions in the model, which can affect the heat transfer effect in blade repairing. In addition, uncertain factors, such as room temperature, heat transfer in protective air, and the effect of clamping force on heat transfer, may affect the experimental results. We will continue to study the refinement and validation of model parameters in further study.

\section{Conclusions}

In this study, theoretical modeling, numerical analysis, and experimental verification are carried out for the optimal heat input of ultrathin aero compressor blade additive manufacturing repair. The optimal heat input range is obtained by the gradual derivation of heat source modeling and numerical analysis, heat transfer modeling and numerical analysis, and experiment verification.

(1) With a planar double elliptical heat source model, a moving heat source model for $1 \mathrm{~mm}$ ultrathin Inconel 718 blade in additive manufacturing repairing was established and optimized by numerical analysis and experimental comparison. The numerical model has good linearity, and by adjusting the geometry of the heat source on the $x-y$ plane, the optimal geometric parameters $\left(a_{f}=1.8 \mathrm{~mm}\right.$, $b_{h}=1.8 \mathrm{~mm}, a_{r}=2.2 \mathrm{~mm}$ ) of the heat source model for ultrathin blade repair were obtained and well 
applied to the following heat transfer modeling and numerical analysis.

(2) Based on the optimal heat source model, a heat transfer model was established based on the optimal heat source model. By analyzing the thermophysical properties of different alloys, the heat input range of the blade was deduced between 374 and $561 \mathrm{~W}$. By heat transfer calculation under different heat inputs, the heat transfer model of blade repair was optimized. Then, a mathematical model of additive height is established. After calculation, the suitable model parameters of wire feeding speed of $2.54 \mathrm{~mm} / \mathrm{s}$ $(6 \mathrm{in} / \mathrm{min})$ and $3.39 \mathrm{~mm} / \mathrm{s}(8 \mathrm{in} / \mathrm{min})$ were obtained to solve the temperature distribution of the additive section with time through numerical analysis, which further reduced the heat input range.

(3) Four groups of experimental parameters were applied to conduct welding experiments and tests. The results show that the segregation degree of additive manufacturing zone decreased with the increase of heat input ratio, it almost disappeared under the parameters of Expt. 4, and the test data were close to the base metal, which signified the additive manufacturing zone achieved better quality. The experimental results are consistent with the trend of simulation prediction, which confirm the validity of the methods and the calculations.

(4) For $1 \mathrm{~mm}$ compressor blade in MPAW additive manufacturing repairing, when the heat input power is $431 \mathrm{~W}$ (voltage $28 \mathrm{~V}$, current $15.4 \mathrm{~A}$ ), the wire feeding speed is $2.54 \mathrm{~mm} / \mathrm{s}(6 \mathrm{in} / \mathrm{min})$ and heat source moving speed is $1.27 \mathrm{~mm} / \mathrm{s}$ ( $3 \mathrm{in} / \mathrm{min}$ ); the additive manufacturing zone can achieve better repair quality. In addition, using parameters of Expt. 4 can effectively reduce the difficulty and time of the postheat treatment process of the aero-engine compressor blades, improve the blade repair efficiency, and reduce the influence of the postheat treatment process on the original mechanical properties of the entire blade.

\section{Data Availability}

The data used to support the findings of this study are included within the article.

\section{Conflicts of Interest}

The authors declare that they have no conflicts of interest.

\section{Acknowledgments}

The authors thank the National Key R\&D Program of China (2019YFB1311104) and the Special Fund for the Central Government to Guide the Development of Local Science and Technology (19941603G) for the support in this study.

\section{References}

[1] V. Ramaswamy, P. R. Swann, and D. R. F. West, "Observation on intermetallic compound and carbide precipitation in two commercial nickel-base superalloys," Journal of the LessCommon Metals, vol. 27, p. 1, 1972.

[2] J. Ye, American Nickel-Based Superalloy, Science Press, Beijing, China, 1978.

[3] C. John, "CFM56 'Evolution' in work for A320," Flight International, vol. 177, p. 5221, 2010.

[4] L. H. S. Barbosa, P. J. Modenesi, L. B. Godefroid, and A. R. Arias, "Fatigue crack growth rates on the weld metal of high heat input submerged arc welding," International Journal of Fatigue, vol. 119, pp. 43-51, 2019.

[5] H. Dai, X. Xi-wei, F. Nai-wen et al., "Effect of the heat input on microstructure and properties of submerged arc welded joint of $08 \mathrm{Cr} 19 \mathrm{MnNi} 3 \mathrm{Cu} 2 \mathrm{~N}$ stainless steel," China Welding, vol. 28, no. 3, pp. 48-53, 2019.

[6] E. Ahmed, R. Ahmed, A. Nikhaily et al., "Effect of heat input and filler metals on weld strength of gas tungsten arc welding of AISI 316 weldments," China Welding, vol. 29, no. 1, pp. 8-16, 2020.

[7] M. Baruah and S. Bag, "Influence of heat input in microwelding of titanium alloy by micro plasma arc," Journal of Materials Processing Technology, vol. 231, pp. 100-112, 2016.

[8] R. S. Desai and S. Bag, "Influence of displacement constraints in thermomechanical analysis of laser micro-spot welding process," Journal of Manufacturing Processes, vol. 16, no. 2, pp. 264-275, 2014.

[9] V. Manvatkar, A. De, L.-E. Svensson, and T. DebRoy, "Cooling rates and peak temperatures during friction stir welding of a high-carbon steel," Scripta Materialia, vol. 94, pp. 36-39, 2015.

[10] L. Zhang, W. Wu, L. Lu et al., "Effect of heat input parameters on temperature field in Inconel718 alloy during selective laser melting," Journal of Materials Engineering, vol. 46, no. 7, pp. 29-35, 2018.

[11] D. Zhang, H. Cui, S. Yang et al., "Microstructures and micro fissuring in the HAZ of Inconel718 welds by laser welding," Materials Reports, vol. 30, no. 8, pp. 96-99, 2016.

[12] X. L. Gao, L. J. Zhang, J. Liu et al., "Effects of weld crosssection profiles and microstructure on properties of pulsed Nd: YAG laser welding of ti6al4v sheet," The International Journal of Advanced Manufacturing Technology, vol. 72, no. 58, pp. 895-903, 2014.

[13] J. Durocher and N. L. Richards, "Evaluation of the low heat input process for weld repair of nickel-base superalloys," Journal of Materials Engineering and Performance, vol. 20, no. 7, pp. 1294-1303, 2011.

[14] S. Saravanan, N. Sivagurumanikandan, and K. Raghukandan, "Effect of heat input on microstructure and mechanical properties of Nd: YAG laser welded super duplex stainless steel-numerical and experimental approach," Optik, vol. 185, pp. 447-455, 2019.

[15] C. Wu, X. Meng, J. Chen et al., "Progress in numerical simulation of thermal processes and weld pool behaviors in fusion welding," Journal of Mechanical Engineering, vol. 54, no. 2, pp. 1-15, 2018.

[16] A. Thakur, N. L. Richards, and M. C. Chaturvedi, "On crackfree welding of cast Inconel 738," International Journal for the Joining of Materials, vol. 15, no. 4, pp. 21-25, 2003.

[17] K. Banerjee, N. L. Richards, and M. C. Chaturvedi, "Effect of filler alloys on heat-affected zone cracking in preweld heat- 
treated IN-738 LC gas-tungsten-arc welds," Metallurgical and Materials Transactions A, vol. 36, no. 7, pp. 1881-1890, 2005.

[18] A. Benoit, S. Jobez, P. Paillard, V. Klosek, and T. Baudin, "Study of Inconel 718 weldability using MIG CMT process," Science and Technology of Welding and Joining, vol. 16, no. 6, pp. 477-482, 2011.

[19] X. Ye, X. Hua, M. Wang, and S. Lou, "Controlling hot cracking in Ni-based Inconel-718 superalloy cast sheets during tungsten inert gas welding," Journal of Materials Processing Technology, vol. 222, pp. 381-390, 2015.

[20] X. Ye, X.-m. Hua, Y.-x. Wu et al., "Microstructure evolution of HAZ of TIG welded Ni-based 718 superalloy," Transactions of The China Welding Institution, vol. 36, no. 8, pp. 97-100+118, 2015.

[21] L. Wang, Y. Yao, J. Dong, and M. Zhang, "Effect of cooling rates on segregation and density variation in the mushy zone during solidification of superalloy Inconel 718," Chemical Engineering Communications, vol. 197, no. 12, pp. 1571-1585, 2010.

[22] S. G. K. Manikandan, D. Sivakumar, K. P. Rao, and M. Kamaraj, "Effect of weld cooling rate on Laves phase formation in Inconel 718 fusion zone," Journal of Materials Processing Technology, vol. 214, no. 2, pp. 358-364, 2014.

[23] S. G. K. Manikandan, D. Sivakumar, M. Kamaraj, and K. P. Rao, "Laves phase control in Inconel 718 weldments," Materials Science Forum, vol. 710, pp. 614-619, 2012.

[24] R. J. Bai and L. G. Zhang, "Turbine blade repairing and its market analysis," Aviation Manufacturing Technology, vol. 12, pp. 37-40, 2002.

[25] H. Wang, L. Wang, T. Wang et al., "Method and implementation of remanufacturing and repair of aircraft engine damaged blade," Acta Aeronautica et Astronautica Sinica, vol. 37, no. 3, pp. 1036-1048, 2016.

[26] H. Liu, H. Chen, W. Liu et al., "Numerical analysis of flowthermal coupling in micro-plasma welding pool of thin-wall part," China Welding, vol. 27, no. 2, pp. 13-18, 2018.

[27] J. Chen, C. S. Wu, and M. A. Chen, "Improvement of welding heat source models for TIG-MIG hybrid welding process," Journal of Manufacturing Processes, vol. 16, no. 4, pp. 485-493, 2014.

[28] J. Goldak, A. Chakravarti, and M. Bibby, "A new finite element model for welding heat sources," Metallurgical Transactions B, vol. 15, no. 2, pp. 299-305, 1984.

[29] F. P. Incropera, D. P. DeWitt, T. L. Bergman et al., Fundamentals of Heat and Mass Transfer, John Wiley \& Sons, Hoboken, NJ, USA, 6th ed. edition, 2006.

[30] M. Gong, S. Dai, P. Jia et al., "Heat transfer modeling and cooling method for aeroengine blade MPAW Repair," Transactions of The China Welding Institution, vol. 40, no. 7, pp. 24-30+162, 2019.

[31] N. Jonas, B. Frank, and A. F. H. Kaplan, "Measuring the effects of a laser beam on melt pool fluctuation in arc additive manufacturing," Rapid Prototyping Journal, vol. 25, no. 3, pp. 488-495, 2019.

[32] Q. Tang, C. Jing-qing, C. Peng, Y. Chen, and Y. Zhao, "Finite element simulation of melting heat accumulation in laser additive manufacturing," Transactions of The China Welding Institution, vol. 40, no. 7, pp. 100-104+165, 2019.

[33] Z. Luo, Y. Zhang, and P. Jia, "Additive manufacturing of Ti$6 \mathrm{Al}-4 \mathrm{~V}$ titanium alloy parts based on micro-plasma arc surfacing," Welding, vol. 04, pp. 13-16+73, 2016.

[34] F. Liu, X. Lin, H. Leng et al., "Microstructural changes in a laser solid forming Inconel 718 superalloy thin wall in the deposition direction," Optics \& Laser Technology, vol. 45, no. 2, pp. 330-335, 2013.

[35] S. G. K. Manikandan, D. Sivakumar, K. Prasad Rao, and M. Kamaraj, "Microstructural characterization of liquid nitrogen cooled alloy 718 fusion zone," Journal of Materials Processing Technology, vol. 214, no. 12, pp. 3141-3149, 2014. 